\title{
Seismic Strengthening of Existing RC Buildings With External Cross-Laminated Timber (CLT) Walls Hosting an Integrated Energetic and Architectural Renovation
}

\section{Lorenzo Badini}

TUM: Technische Universitat Munchen

Dr.-Ing. Patrik Aondio ( $\nabla$ aondio@tum.de)

TUM: Technische Universitat Munchen https://orcid.org/0000-0002-7266-1292

\section{Stephan Ott}

TUM: Technische Universitat Munchen

\section{Stefan Winter}

TUM: Technische Universitat Munchen

\section{Research Article}

Keywords: Cross-laminated timber, existing building, seismic retrofit, target displacement, energy retrofit, numerical analyses

Posted Date: December 15th, 2021

DOI: https://doi.org/10.21203/rs.3.rs-1158976/v1

License: (c) (1) This work is licensed under a Creative Commons Attribution 4.0 International License.

Read Full License 


\title{
Seismic strengthening of existing RC buildings with external cross-laminated timber (CLT) walls hosting an integrated energetic and architectural renovation
}

\author{
Lorenzo Badini $\odot^{1}$, Stephan Ott $\odot^{2}$, Patrik Aondio $\odot^{3 *}$, Stefan Winter $\odot^{4}$
}

${ }^{1}$ Chair of Timber Structures and Building Construction, Technical University of Munich, Munich, Germany; Department of Architecture, University of Bologna, Bologna, Italy

e-mail: lorenzo.badini@tum.de; lorenzo.badini3@unibo.it

${ }^{2}$ Chair of Timber Structures and Building Construction, Technical University of Munich, Munich, Germany

e-mail: ott@tum.de

${ }^{3}$ Chair of Timber Structures and Building Construction, Technical University of Munich, Munich, Germany

* corresponding author: Dr.-Ing. Patrik Aondio, fellow researcher at the Chair of Timber Structures and Building Construction, Technical University of Munich, Arcistraße 21, 80333 Munich, Germany; e-mail: aondio@tum.de

${ }^{4}$ Chair of Timber Structures and Building Construction, Technical University of Munich, Munich, Germany

e-mail: winter@tum.de

\begin{abstract}
In this study a timber-based integrated solution is presented to solve at once common issues affecting typical reinforced concrete (RC) existing buildings, such as seismic and energy performances, providing an eco-friendly alternative to steel external bracing systems. Cross-laminated timber (CLT) walls are provided perpendicularly to the external façades as strengthening elements while interposed CLT slabs are foreseen at each floor level to host new architectural units together with a new envelope. While the connections to the foundations and to the existing RC frames are provided respectively with steel brackets and axial-connectors distributed along the height of the building, a post-tensioned connection, between CLT panels (PT-CLT connection), is implemented in the system to guarantee resistance to horizontal actions acting parallel to existing façades with consequent structural independence and architectural freedom. A numerical model is developed with finite element software characterizing each type of connector for linear and non-linear analyses. Modal analyses with response spectrum are performed to verify structural elements and connectors, while pushover analyses with target displacement checks are performed to assess the obtained seismic improvement. Finally, the preassembled architectural components that allow to renovate the envelope and the provided assembly procedure are revealed.
\end{abstract}

KEYWORDS: Cross-laminated timber, existing building, seismic retrofit, target displacement, energy retrofit, numerical analyses 


\section{INTRODUCTION}

The renovation of existing building stock is an increasingly important topic, due to the progressive deterioration of the major part of the buildings, designed and realized between the 50's and the 90's. The European Union counts about 200 million existing units, representing around 27\% of total energy consumption (Ferrante et al. 2018). Furthermore, many of these are located in seismically active areas and designed without any reference to horizontal loads or follow outdated standards. This is the main context of Pro-GET-onE research and innovation project, whose main objective is the design, verification and assessment of an integrated technological system to be assembled externally to existing reinforced concrete (RC) structures in order to obtain a seismic and energy improvement that at the same time offers additional space for extended housing units (Ferrante et al. 2018). The structural seismic improvement has been proven with a steel threedimensional exoskeleton (Badini et al. 2019; Fotopoulou et al. 2018). Seismic analyses have been performed through FEM software before and after the application, to existing RC structures, of the strengthening steelbased exoskeleton, showing that the increase in strength and stiffness of the entire building is usually associated with an increase in capacity and a reduction of displacements. Complementary to the external structure, architectural components are developed for the extensions of the building envelope (Ferrante et al. 2018; Fotopoulou et al. 2019; Ott and Krechel 2018). The pre-assembled solutions had to face the challenges of architecture variability (extra-room, sunspace, and balcony), completing the strengthening structure, and were provided as prefabricated boxes or slabs composed by combinations of cross laminated timber (CLT) panels and wooden frames. Together with the increased space delivered by the extension of the exoskeleton, airtightness, insulation, and new façade is provided by the components. These interventions result in higher energy efficiency, renewal of the building envelope, thus updated asset value (Ferrante et al. 2018). Combined with new and efficient heat, ventilation, and air conditioning (HVAC) systems, their piping, and the inclusion of renewable energy sources (RES) on the roof, the architectural components aim to achieve the level of nearly zero energy building (Assimakopoulos et al. 2018; Barmparesos et al. 2019; Ferrante et al. 2019). Worth mentioning are also the contributions that address the environmental impact of the project (Luca Guardigli et al. 2019a; L. Guardigli et al. 2019b), comparing different scenarios within the prototype-renovation and against the process of demolition and rebuild. From the LCA it is calculated that over a period of analysis of 50 years, out of a total of about 700 tonnes of $\mathrm{CO}_{2 \mathrm{e}}$ related to the whole renovation, $35 \%$ is due to the external steel structure. It is clear that to further address climate change mitigation and minimise the environmental impact, alternative structural solutions should be investigated.

In the last decades, as consequence of an accelerated drive towards sustainable materials, the rediscovery of wood as a structural material has led to the spread of new engineering wood products and related research (citing only mass timber products, laminated veneer and strand lumber and cross-laminated timber). In particular, CLT panels are produced to a high degree of prefabrication which allows efficient and safe on-site installation and they have been applied globally in many low-rise and mid-rise buildings typically using platform construction technology (Dangel 2018). Under seismic loads, CLT shear walls with properly designed connection systems are able to provide adequate lateral capacity for multi-storey buildings. Despite the lightness of the material which allows to have low values of mass, a higher level of lateral in-plane strength and stiffness can be reached (Dujic et al. 2008). These qualities make it a product that is easily applicable for extensions (Hristovski et al. 2018; Iztok Sustersic et al. 2010) or renovation of existing buildings (Margani et al. 2020; Mora et al. 2015; Stazi et al. 2019; Iztok Sustersic and Dujic 2012; 2013; 2014a; I. Sustersic and Dujic 2014b). In Slovenia, Sustersic I. and Dujic B. evaluated a new system for combined seismic retrofit and energy efficiency that exploited the CLT panels applied in parallel to the façades of an existing RC-building (Iztok Sustersic and Dujic 2012). The CLT jacket, depending on the dimensions of the applied panels, reveals itself as a not invasive intervention that is rigidly connected to the $\mathrm{RC}$ frames by means of angular brackets nailed to the wood and fixed with bolts to the concrete slabs. It proved to increase stiffness and strength of the entire existing RC structure without influencing the global ductility. Furthermore, the CLT panels can be upgraded with various insulation types implying an integrated energetic renovation. The same system was then developed and optimised on RC frames and in combination with masonry unreinforced structures, where 
through the variation of the bonding system or the connectors, an increase in ductility was provided. Furthermore, the system has demonstrated the possibility of increasing the performance of already severely damaged structures (Iztok Sustersic and Dujic 2013; 2014a; I. Sustersic and Dujic 2014b). In this context, from the University of Venice (IUAV), studies were conducted in order to characterise layering configurations applied on CLT-strengthening panels, taking into account minimisation of heat-losses, environmental impacts and intervention costs (Mora et al. 2015). More recently, a similar solution has been proposed in (Margani et al. 2020) that foresees again an outer shell made of CLT panels combined with an insulation layer within additional timber framework. Simulations on the system have demonstrated the reduction on energy demand, technical details are aimed at developing a pre-assembled system that can be easily assembled from the outside with dry components, exploiting a new friction-based dissipative connection between the panels and the RC frames. Finally, confined and unconfined CLT panels were studied also as new infills for RC frames showing a substantial reduction in lateral displacement complemented by higher peak load capacity (Stazi et al. 2019).

The study presented in this article will describe an innovative and integrated system that together with energetic and structural improvements, entails the possibility of increasing the volume of existing buildings with consequent increased value of the real estate that could further mitigate the renovation costs.

\section{INTEGRATED SYSTEM}

In accordance with the philosophy of the EU project, it was necessary to develop an integrated system capable of satisfying all the three principal objectives (seismic safety, energetic improvement, and additional space). By means of external performing façades or extensions, prefabricated wooden components can easily be installed with effective results (Lattke et al. 2011; Pihelo et al. 2017).

Within the contents of Pro-GET-onE three case studies are provided: a moment-resisting RC frame located in Athens (Greece), a hybrid masonry-RC structure in Bagnolo in Piano (Italy), a precast concrete walls structure in Brasov (Romania). The latter has been chosen as reference structure due to the climatic conditions of the area, and the local availability of wood. It is a five-stories homeless dormitory built in 1972, characterised by a superstructure made of prefabricated RC walls (Fig. 1a). More information about this case study is reported in (Maslaev Consulting 2015; Pro-GET-onE Consortium 2018). In the reports it is highlighted that the energy performance is poor with reference to winter consumptions and domestic hot water production and that an architectural renovation is required due to the change of use to social housing block of flats (Fig. 1b). This contrasts with a general good performance concerning the seismic vulnerability assessment. Three indicators are reported with as many procedures: a qualitative assessment based on tables, assessment of the degradation stage from visual and detailed examinations and quantitative assessment based on static linear analysis and capacity/demand ratios for each wall at the base level. Based on the result of the latter, the report states that the building suffers moderate vulnerability and that the structural intervention to consolidate it is not necessary. For this reason, the integrated timber-based system was developed as architectural independent extension for the case study, providing a complete energy renovation of the envelope. A virtual moment-resisting RC structure designed for vertical loads only and with a morphology as close as possible to the Romanian case study (considering spanning changes due to a different structural system) was then numerically investigated in combination with the timber-based strengthening system to prove the seismic improvement. All the data related to the $\mathrm{RC}$ frames are reported in chapter 3 as description of the initial state FEM model (Figure 13). 

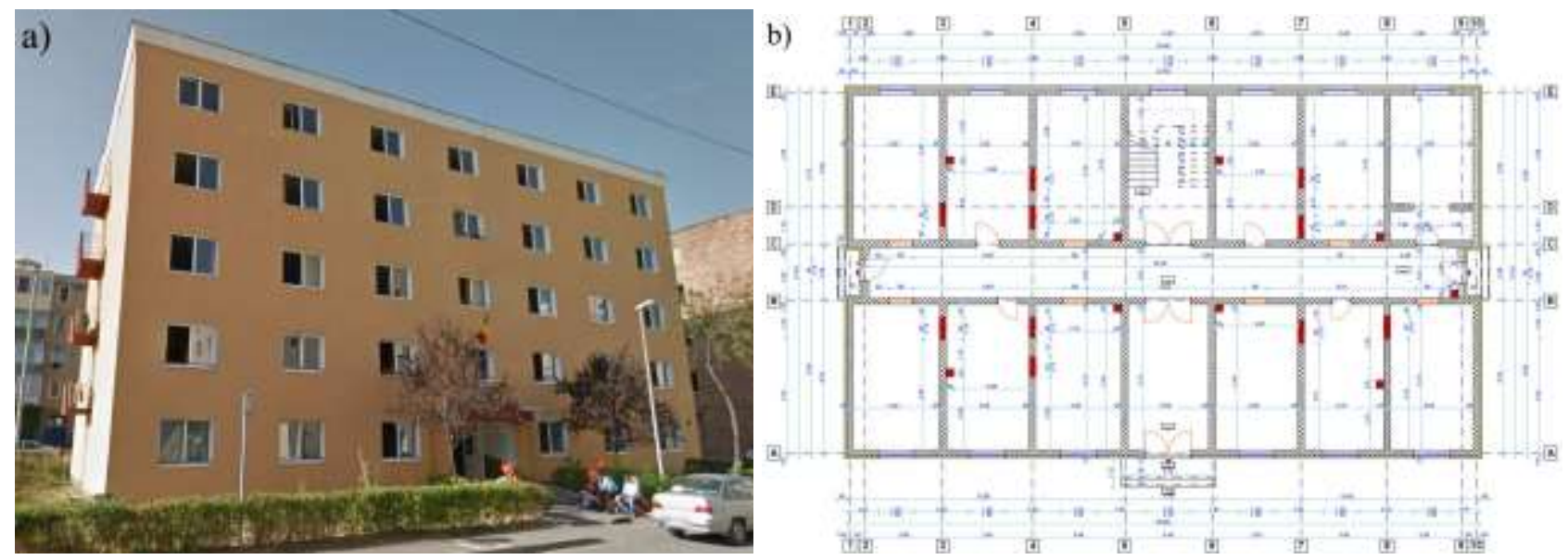

Fig. 1 a) Photo of the precast-concrete walls case study in Brasov; b) Typical plan of the case study including the architectural renovation provided for the internal partitions

CLT walls constitute the structural strengthening system for the existing structure and are externally added in continuity of the RC frames, in the plane perpendicular to the external façades. They improve the seismic performance increasing the global stiffness of the system, reducing the displacement demand, and increasing the capacity by avoiding concentration of damages in the lower levels. CLT slabs are then provided horizontally creating a "bookshelf" in which the different architectural solutions are provided, guaranteeing the new performing envelopes (Fig. 2).

While the vertical walls are made of $200 \mathrm{~mm}$ thick CLT panels composed of five layers of birch (40-40-4040-40 mm) (Jeitler et al. 2016), the slabs are made of $160 \mathrm{~mm}$ CLT spruce panels with five layers (40-20-40$20-40 \mathrm{~mm}$ ) and are connected at each floor by means of a moment-resisting post-tensioned connection that adapts the analytical behaviour presented by F. Wanninger and A. Frangi $(2014 ; 2016)$. The strength values of the timber CLT are summarised in Table 1.

Table 1 Characteristic strength and stiffness properties in MPa for CLT-Spruce (ETA-06/0009 - EN 338) and CLT-Birch (Jeitler et al. 2016), plus relative mean density values in $\mathrm{kg} / \mathrm{m}^{3}$

\begin{tabular}{cccc}
\hline Value & Units & CLT-Spruce & CLT-Birch \\
\hline$f_{m, C L T, k}$ & $\mathrm{MPa}$ & 24 & 38 \\
\hline$f_{c, 0, C L T, k}$ & $\mathrm{MPa}$ & 21 & 38 \\
\hline$f_{c, 90, C L T, k}$ & $\mathrm{MPa}$ & 2.5 & 5.0 \\
\hline$f_{t, 0, C L T, k}$ & $\mathrm{MPa}$ & 14 & 28.5 \\
\hline$E_{0, C L T, \text { mean }}$ & $\mathrm{MPa}$ & $12^{\prime} 000$ & $15^{\prime} 000$ \\
\hline$E_{90, \text { CLT,mean }}$ & $\mathrm{MPa}$ & 370 & 650 \\
\hline$G_{C L T, \text { mean }}$ & $\mathrm{MPa}$ & 690 & 710 \\
\hline$\rho_{\text {CLT,mean }}$ & $\mathrm{kg} / \mathrm{m}^{3}$ & 470 & 620 \\
\hline
\end{tabular}

Both the connections to the foundations and to the existing structures are made with consolidated and simplified solutions in order to minimise the uncertainties on the numerical analyses and leaving space for further research development. Every wall has been connected to the foundation level with 12 angular brackets (BMF116) and 16 hold-downs (HTT22), distributed on both side of the $2 \mathrm{~m}$ width CLT panels. The connection 
with the existing structure is designed to transmit only the axial loads acting in direction perpendicular to the existing façade, allowing the interaction between the two structures only for horizontal actions acting in-plane to the CLT walls.
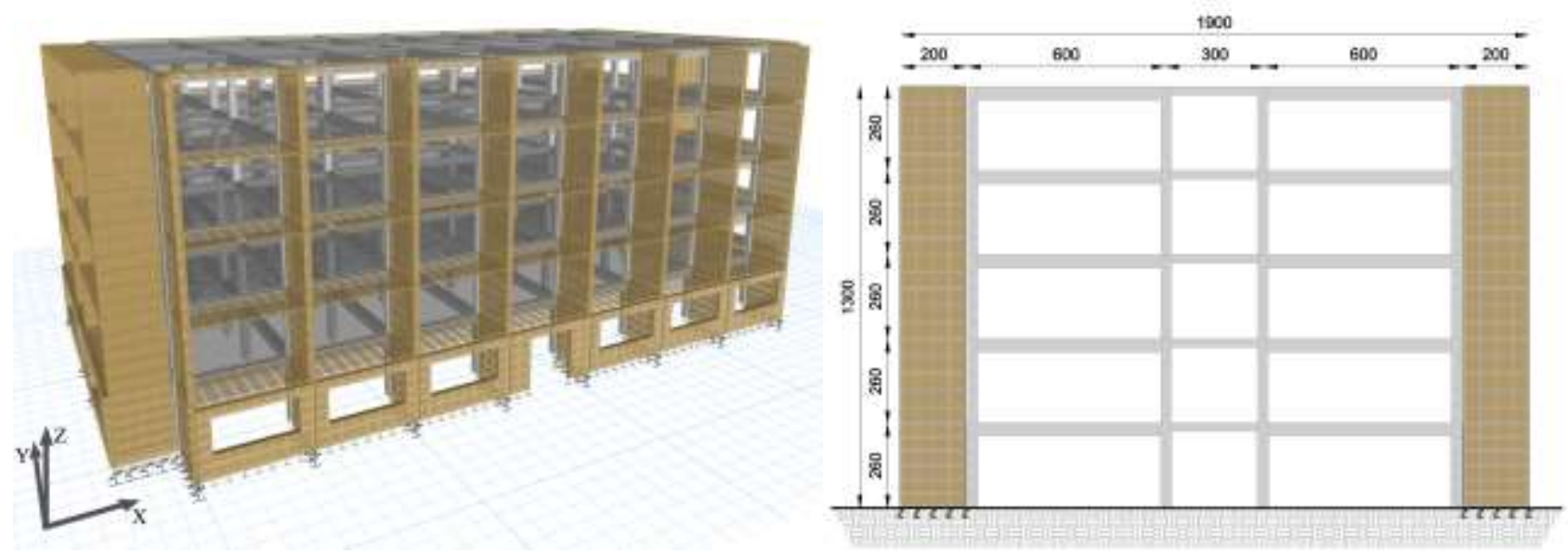

Fig. 2 Finite element model of the CLT-based strengthening system applied to four sides of the building: perspective view and dimensioned vertical cross-section

\subsection{PT-CLT CONNECTIONS}

Adapting concepts and principles originally developed for precast concrete construction (Priestley et al. 1999), post-tensioned (PT) timber systems have been developed and tested since 2005 at the University of Canterbury (Palermo et al. 2005). The technology takes advantage of unbonded post-tensioned steel tendons passing through internal cavities in timber beams or walls to create a moment resisting connection. The seismic demand is satisfied through controlled rocking between structural elements and tendon elongation, which also ensures recentring capabilities. Thus, energy-dissipation devices (replaceable mild steel components, viscous or friction dampers) could be provided creating hybrid connections characterised by the typical flag-shaped behavioural law (see Fig. 3). For the sake of brevity a complete state of the art on Pre-Lam technology is not summarised here, but reference is made to (Granello et al. 2020).

a)

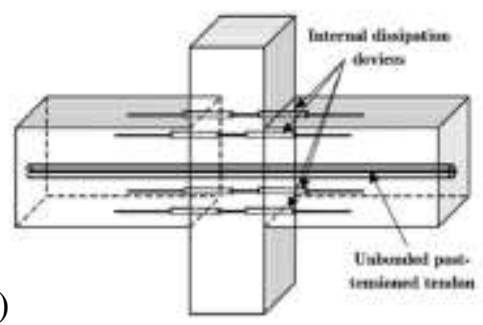

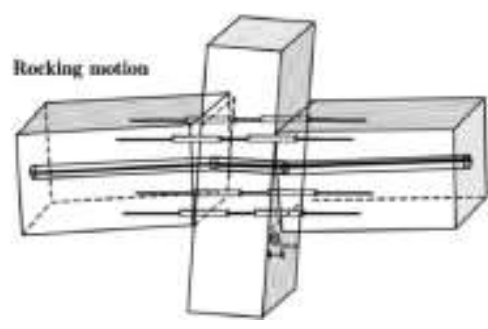

b)

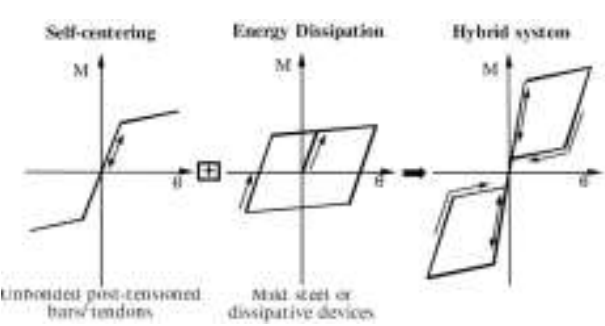

Fig. 3 a) The application of hybrid concept to LVL frame systems (Palermo et al. 2005); b) The idealised flag-shape hysteresis loop (Palermo et al. 2005)

As mentioned in the previous section, direct reference to the analytical method reported in (Wanninger and Frangi 2014; 2016) was made for the adaptation of the PT connection to CLT panels. With difference from the New Zealand experience, at the ETH Zurich the PT frames are developed with glulam made from Norway spruce, and present a reinforcement made of European ash where high stresses perpendicular to grain occur 
(column and bottom side of the beams), avoiding the use of steel reinforcements in the joints. Extensive experimental testing have been performed under both gravity and lateral loads, on single column-beam subassemblies, an entire three-spans frame and ending with the construction of a prototype (Wanninger 2015) (Fig. 4).

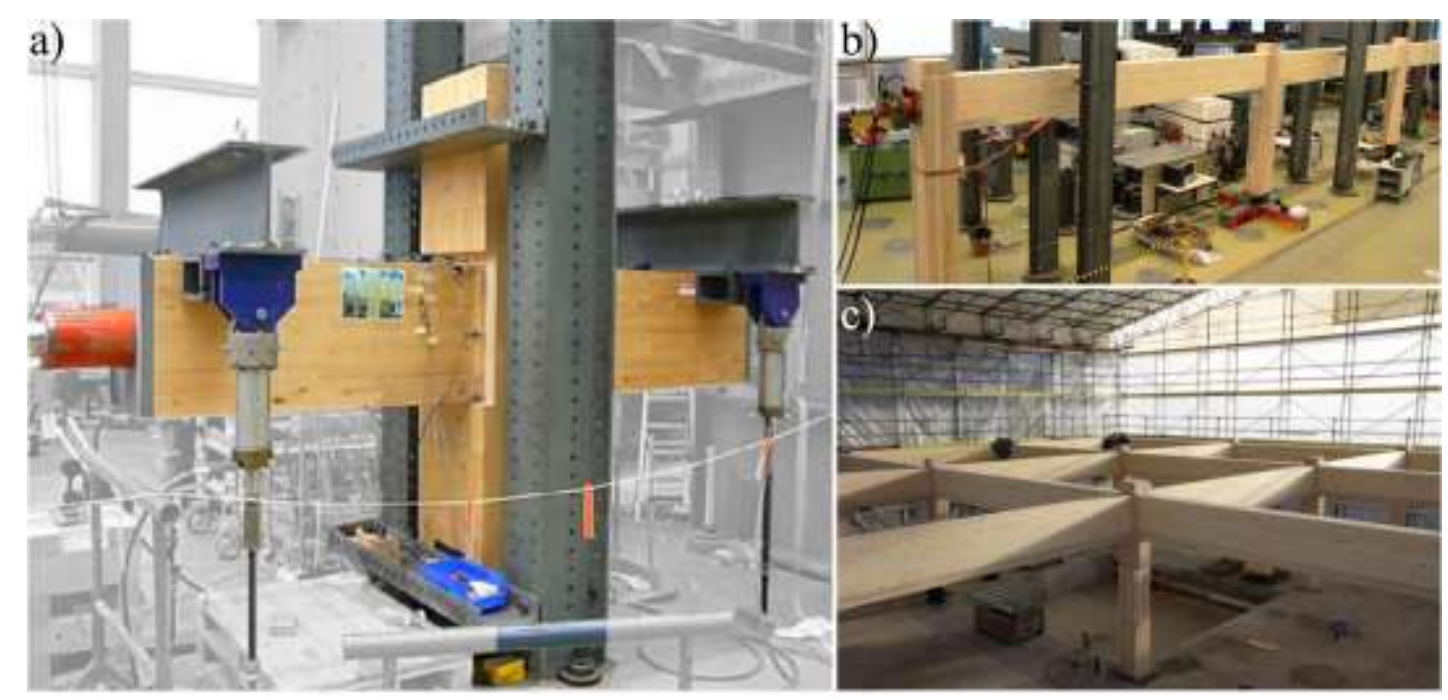

Fig. 4 a) Glulam column-beam specimen; b) Three-spans PT-glulam frame; c) First elevation of the ETH House of Natural Resources (Wanninger 2015)

The analytical model is based on springs that represent the softer column and only bear compressive forces. The beam ends at the interface and behave like a rigid body due to the higher strength and stiffness of the timber components in parallel to grain direction. Hence, the model corresponds to a (stiff) foundation on (soft) ground (Winkler theory) (Wanninger and Frangi 2014). Since there are no dissipating elements, a gap occurs in the interface as soon as there is no compression at either the top or bottom edge of the connection. The analytical model describes the behaviour of the connection (moment-rotation), and based on equilibrium of forces and bending moments at the interface, leads to three stages that depend on the value of the neutral axis $x$ (Fig. 8) (Wanninger 2017; Wanninger and Frangi 2014):

1. Before decompression $(x=h)$; the beam is in full contact with the column. Linear behaviour.

2. After decompression $(x<h)$; a gap occurs at the edge of the beam. Non-linear behaviour.

3. Tendon elongation $(x<h / 2)$; when the neutral axis goes below the tendon, the latter gets elongated, resulting in an increase in tendon force and stiffness. Non-linear behaviour with increased slope.

Asymmetrical loads imply shear deformations in the column that depend on the eccentricity of the resultant compressive forces on the two interfaces of the joints. This occurs in the outer joints and more significantly in the inner ones when subject to horizontal loads as shown in Figure 5. 


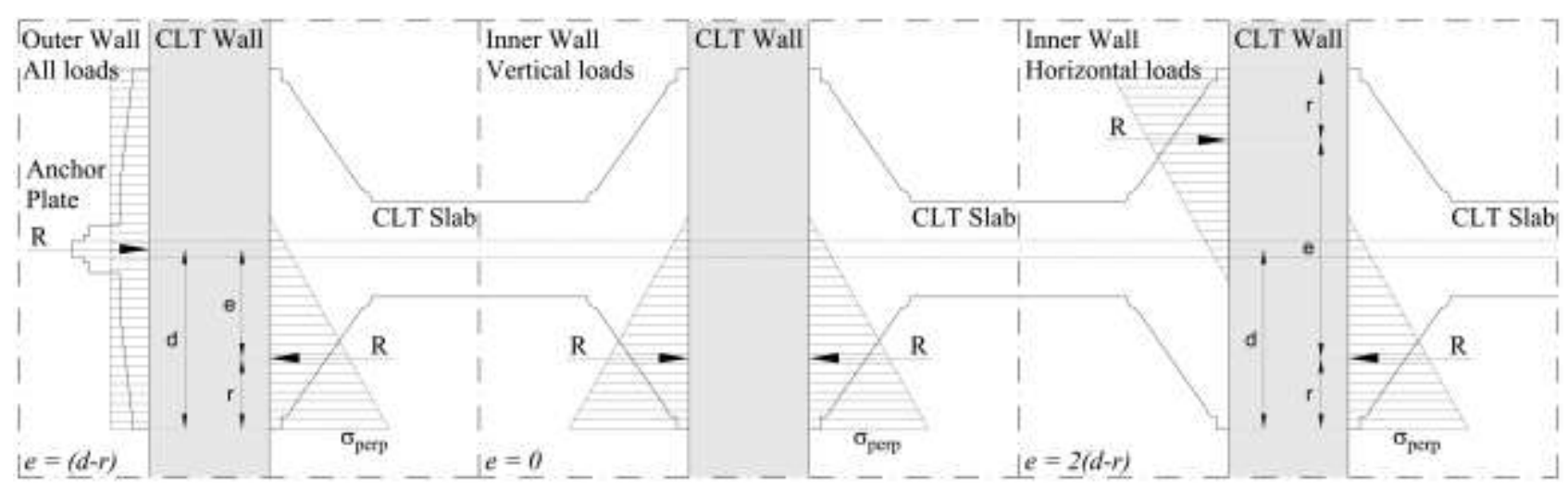

Fig. 5 Distribution of stresses at the connection interfaces of outer and inner walls in the cases of vertical and horizontal loads (VL, HL)

The transition from a beam-column system with linear elements to a system with two-dimensional elements involved the use of a composite steel plate to increase the contact surface between horizontal and vertical elements maintaining adequate rotational stiffness (depending on the height of the horizontal element) without encountering a premature failure of the grain compressed perpendicularly (Fig. 6).

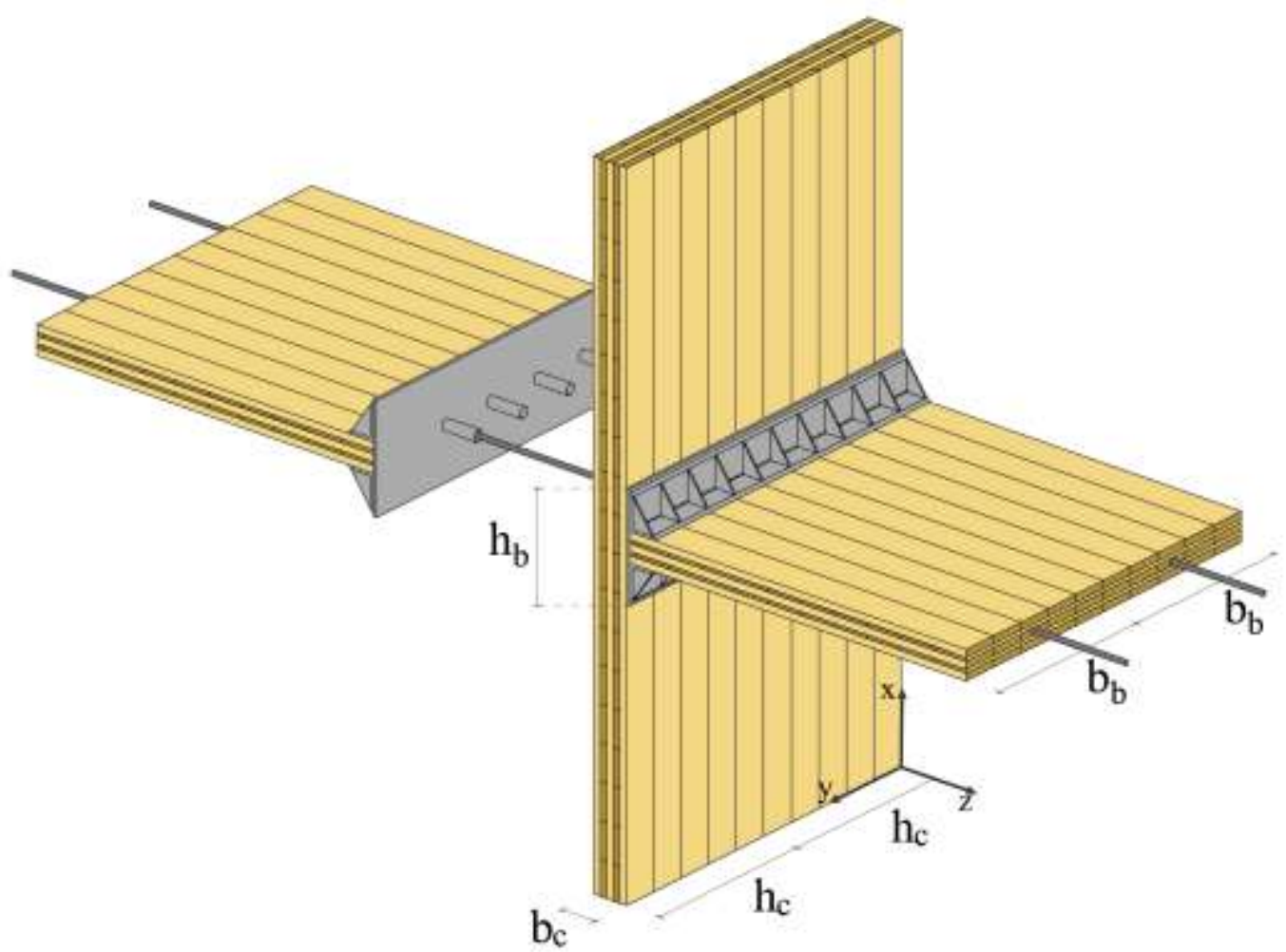

Fig. 6 PT-connection between CLT panels by means of steel unbonded cables and steel composed plates

This connection steel plate is composed by a large steel plate $(600 \times 2000 \mathrm{~mm}) 20 \mathrm{~mm}$ thick, with two angular brackets L $200 \times 150 \times 18 \mathrm{~mm}$ and four steel pipes (Figures 6 and 7). The large plate with the L-profiles allows to increase the height of the horizontal element for the evaluation of the rotational behaviour while the steel tubular profiles are inserted in specific holes of the CLT vertical element to transfer the vertical loads. The holes in the CLT provide tolerances allowing a relative rotation of the plate, and the steel pipes must overlap one another during the assembly of inner joints $(\phi 48.3 \times 2.6 \mathrm{~mm}$ and $\phi 60 \times 2.16 \mathrm{~mm})$. Reinforcing LVL made 
of hardwood is provided at the contact interface between the horizontal CLT element and the smaller side of the angular steel profile to avoid the crushing of the grain. Alternatively, a stiffer external layer could be already provided manufacturing the CLT slabs. The steel unbonded tendon passes through the horizontal elements along their development and across the vertical one. It is composed by four wired strands with cross sectional area about $600 \mathrm{~mm}^{2}$, Young's modulus of $197 \mathrm{GPa}$ and a maximal tension strength about 1,770 MPa (ETA-13/0810 in (BBV Systems 2021)).

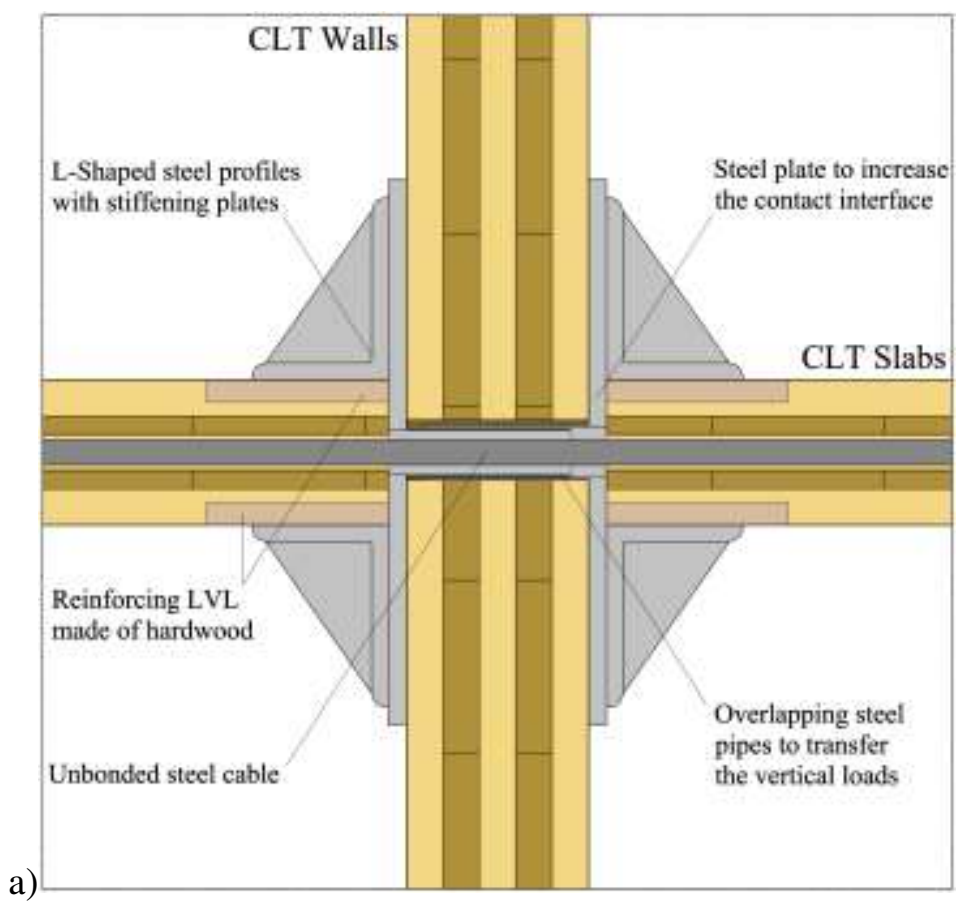

b)

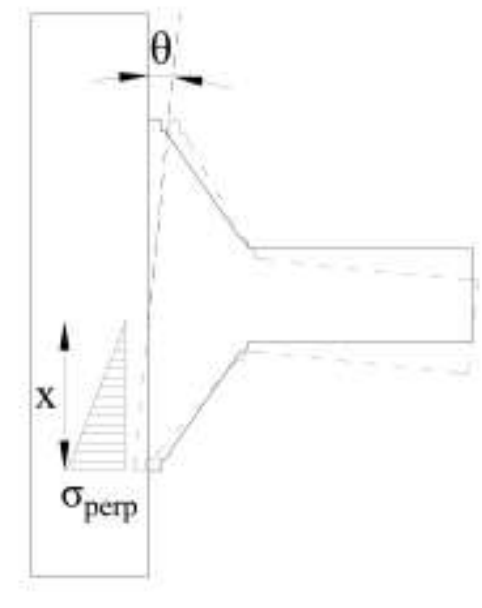

Fig. 7 a) Detail of the PT-CLT connection with steel composed plates; b) Schematic representation of the values resulting from the analytical model (rotation $\theta$, stresses perpendicular to grain in the vertical element $\sigma_{\text {perp }}$ and, neutral axis $\mathrm{x}$ )

Through this system the analytical model presented in (Wanninger and Frangi 2014; 2016) was adapted. In Table 2 a comparison between the input data used for the calculation of the rotational spring is reported with reference to the notations of Figure 6. $S_{x z}$ represent the shear rigidity of the CLT in the $x z$ plan as calculated in (Aondio et al. 2020b).

Table 2 Comparison between the values used in (Wanninger and Frangi 2014), referring to a column specimen made of ash, and the CLT vertical element made of birch. These inputs were used for the calculation of the rotational behaviour (half of the total depth)

\begin{tabular}{cccc}
\hline Value & Units & $\begin{array}{c}\text { D40 (Wanninger and } \\
\text { Frangi 2014) }\end{array}$ & $\begin{array}{c}\text { CLT-Birch (Figure 6 } \\
\text { and Table 1) }\end{array}$ \\
\hline$E_{90, \text { mean }}$ & $\mathrm{MPa}$ & 860 & 650 \\
\hline$G_{0, \text { mean }}$ & $\mathrm{MPa}$ & 810 & - \\
\hline$S_{x z} / b_{c}$ & $\mathrm{MPa}$ & - & 246 \\
\hline$f_{c, 90, k}$ & $\mathrm{MPa}$ & 8.3 & 5 \\
\hline$b_{c}$ & $\mathrm{~mm}$ & 280 & 200 \\
\hline
\end{tabular}




\begin{tabular}{llll}
\hline$h_{c}$ & $\mathrm{~mm}$ & 600 & 1000 \\
\hline$b_{b}$ & $\mathrm{~mm}$ & 400 & 1000 \\
\hline$h_{b}$ & $\mathrm{~mm}$ & 600 & 600 \\
\hline
\end{tabular}

Through the adaptation of the analytical model, it was possible to obtain the laws describing moment, compression perpendicular to grain in the vertical element, neutral axis position and tension in the tendon in relation to the rotation at the interface. With reference to (Wanninger and Frangi 2014; 2016) the equations reported in Table 3 are used to determine the rotational behaviour in the three main phases introduced above.

Table 3 Formulations to determine the rotational behavior of the PT-CLT connection(Wanninger and Frangi 2014).

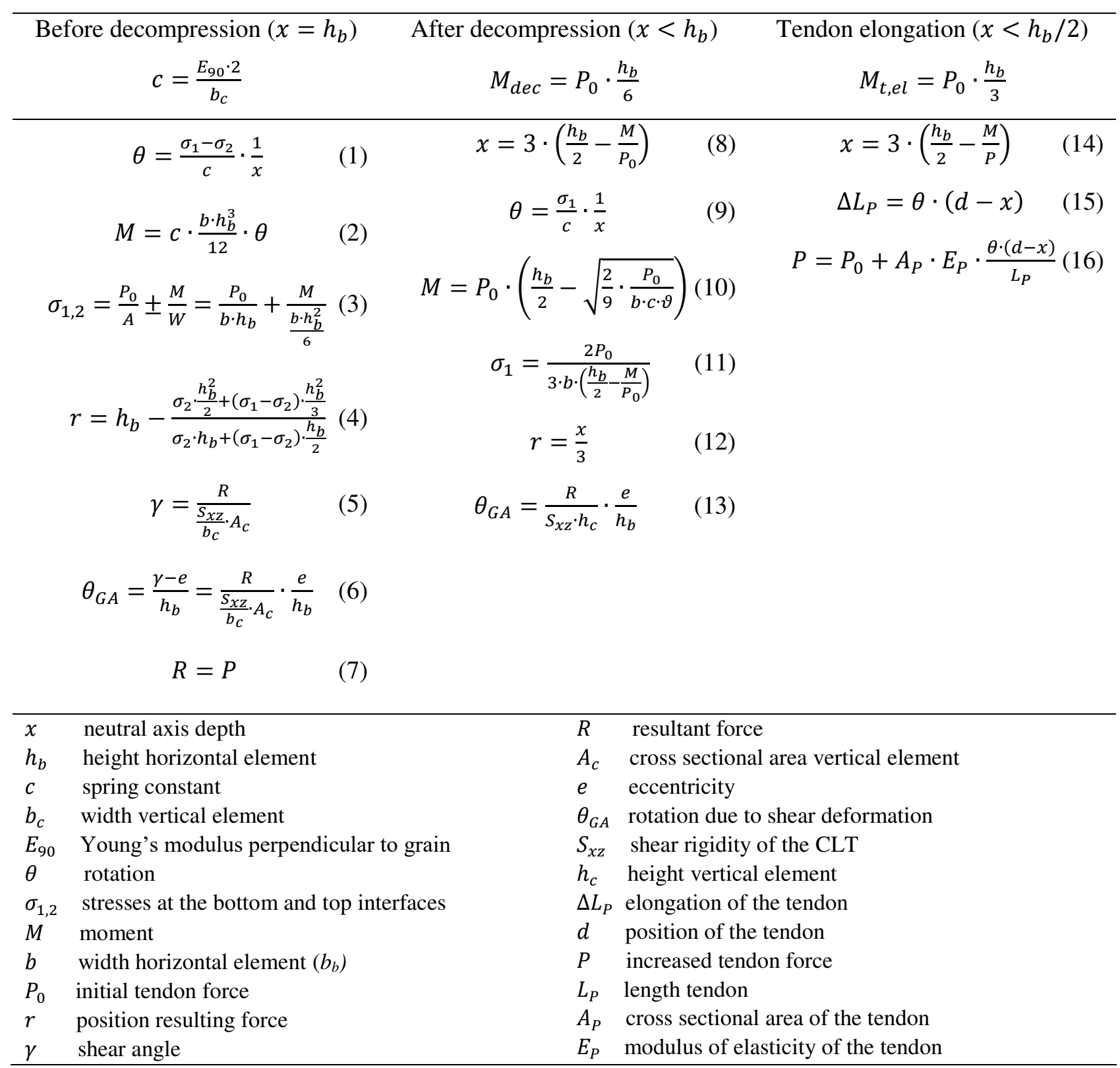

Below in Figure 8 the relationships mentioned above are shown with reference to half of the depth of the system ( $1 \mathrm{~m}$ with one steel cable) and an initial tension $\left(P_{0}\right)$ set to $500 \mathrm{kN}$. It is evident how much relevant is 
the shear deformation of the CLT vertical element on the rotational stiffness due to the lower value $S_{x z} / b_{c}$ compared to $G_{0, \text { mean }}$ from (Wanninger and Frangi 2014).

Finally, it is important to mention that the analytical model developed in (Wanninger and Frangi 2014) was particularly precise until the phase of tendon elongation. In this phase the analytical model was losing precision, overestimating the stiffness and implying the use of an experimental factor to correct the spring stiffness of the analytical model at the beginning of the tendon elongation (Wanninger and Frangi 2014). However, for the purpose of this study, the connection between CLT components is meant to stay in the elastic range under the design seismic loads. Thus, allowing the exploitation of the analytical model without experimental coefficients.
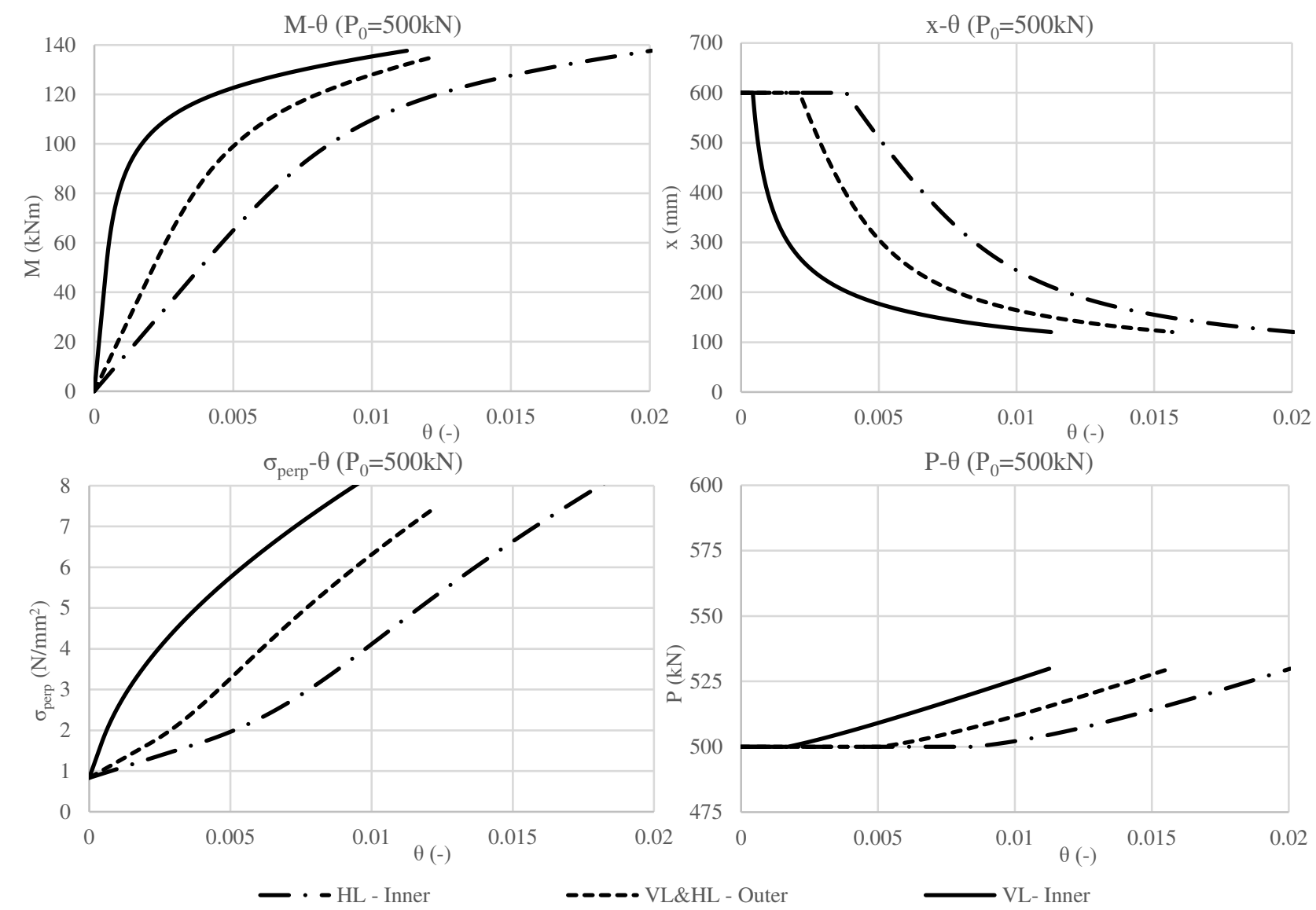

Fig. 8 Moment-rotation behaviour, compression perpendicular to grain, neutral axis position and tension in the tendon in relation to the rotation at the PT-CLT connection interface, calculated for the inner elements with vertical loads (VL) and horizontal loads (HL) and for the outer elements

The failure of the connection is related to the crushing of the grain. From the graphs in Figure 8 it is possible to identify the rotation which corresponds to a compression perpendicular to the grain of the vertical element, which for birch is fixed at $5 \mathrm{MPa}$. In addition, with the equilibrium between the moment at the interface and the prestressing force $P$ it is also possible to determine the force $V$ that defines the stresses at the interface between the steel angle brackets and the pieces of LVL reinforcement, as shown in Figure 9. By estimating the stresses at the interfaces, it was possible to verify the connection against the design loads. A mechanical fixation of the LVL layers to the horizontal element of the CLT would also allow these elements to be replaced in case of major events.

A specific experimental campaign has been performed in order to prove the adaptation of the analytical model to CLT element by means of steel plates and will be the main content for a standalone contribution. 


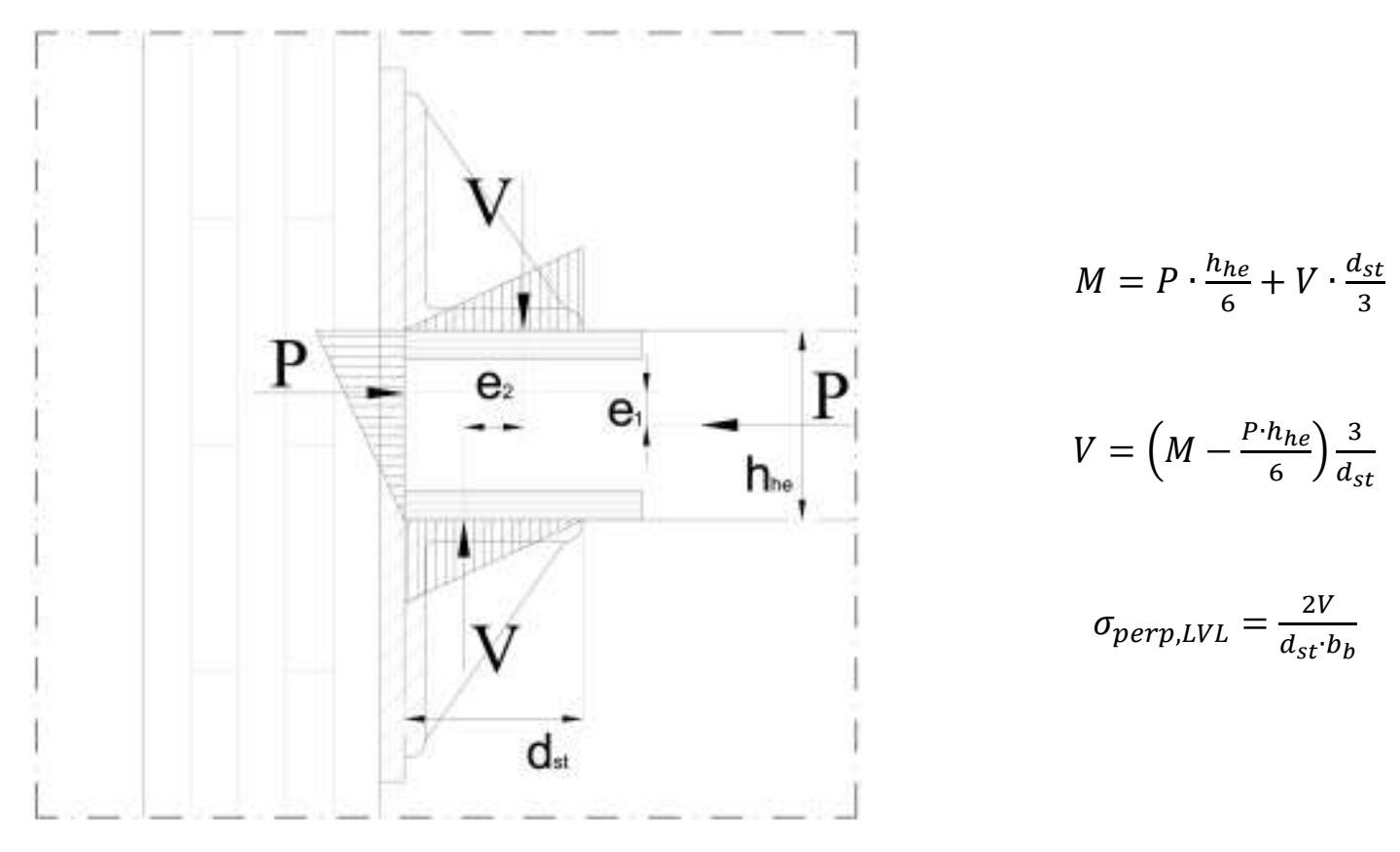

Fig. 9 Forces and stresses affecting the end of the horizontal CLT panel

\subsection{CONNECTORS AT FOUNDATION LEVEL}

The use of hold-downs and angular brackets as connectors for CLT structures is widely spread in construction practice and extensively investigated in research (Dujic et al. 2008; Dujic et al. 2010; Gavric et al. 2015; Iztok Sustersic et al. 2016). Due to this reason typical connectors were exploited at the foundation level distributed on both sides of the CLT walls. With specific reference to (Dujic et al. 2010) commercial products already characterised by linear strength properties, secant stiffness and non-linear behavioural laws were provided:

- 12 angular brackets (BMF $90 \times 48 \times 3 \times 116 \mathrm{~mm}$ ) fastened to the CLT walls with 12 nails (or screws) $\phi 4 / 60 \mathrm{~mm}$ and with $2 \mathrm{M} 12$ bolts to the foundation were provided in the middle of the walls as shear anchors with a contribution also to prevent up-lift loads (see Figure 10);

- 16 hold-downs (HTT22) fastened to the CLT each with 22 nails (or screws) $\phi 4$ / $60 \mathrm{~mm}$ and with 1 M12 bolt to the foundation were placed towards the corners of the walls to resist overturning forces (Figure 10).

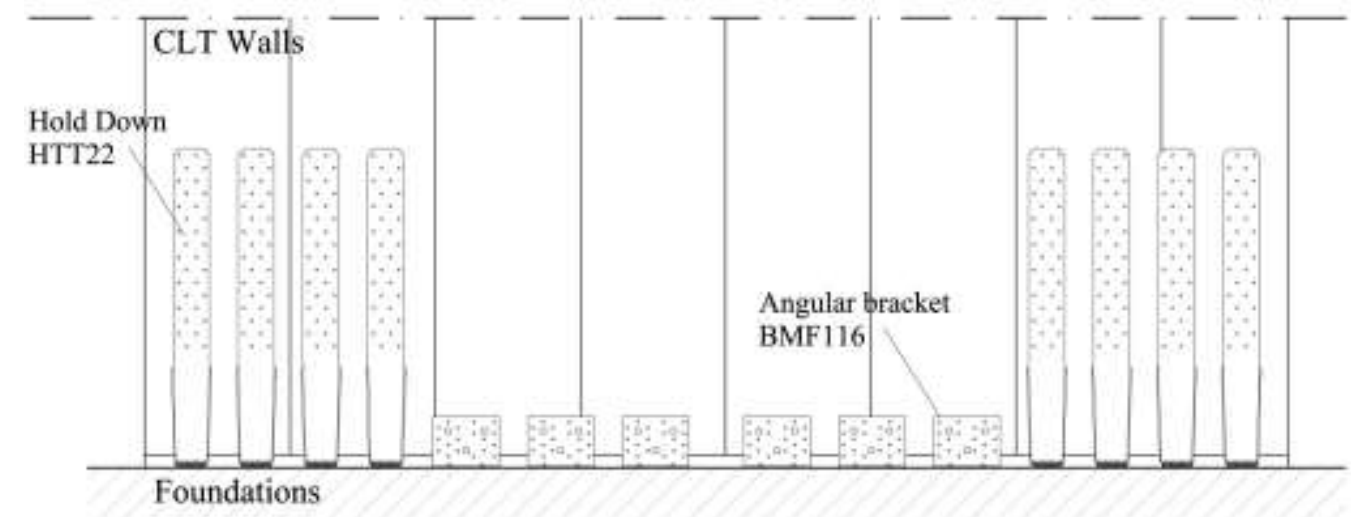

Fig. 10 Multiple connectors at foundation level are represented in the drawing on one side of the CLT wall 
The friction at the foundation level was calculated considering the vertical loads derived from the quasipermanent load combination. Due to the lightweight of the material and the limited dimensions of the external CLT structure, the axial loads in the walls are limited with a consequent small relevance of the friction at the base. Considering a friction coefficient between wood and concrete of 0.62 , the contribution of friction is calculated and exposed below in Table 4 .

Table 4 Activated friction forces at the bottom of the inner and outer walls

\begin{tabular}{cccc}
\hline Value & Units & Inner wall & Outer wall \\
\hline$N$ & $\mathrm{kN}$ & 110.3 & 68.09 \\
\hline$F_{f r}$ & $\mathrm{kN}$ & 68.4 & 42.2 \\
\hline
\end{tabular}

Despite the rapid implementation of the connectors in the numerical model (see Figures 14d, 16, 17), the right number of them was determined iteratively, checking the force-displacement relationship during non-linear static analysis, matching the seismic global safety of the intervention while keeping the connectors (especially the hold-downs located at the edge of the walls) within their maximum allowed displacement.

\subsection{CONNECTION WITH THE EXISTING STRUCTURE}

As mentioned above, the connection with the existing structure is designed to transmit only axial loads acting in-plane to the CLT walls. Twenty connectors are distributed along the height of the building, consisting of steel rods $(\phi 12 / 150 \mathrm{~mm})$ fixed with chemical dowels to the CLT walls and providing steel plates to be anchored at the vertical RC elements (see Figure 11). The threaded galvanised rod made of reinforcing steel (B450C) is characterised by a bilinear stress-strain relationship as shown in Figure 14d. This steel connector plate must provide specific tolerances that allows relative vertical and horizontal displacements. While the relative vertical displacement results in maximum of $5 \mathrm{~mm}$ (a tolerance of $10 \mathrm{~mm}$ is provided), the horizontal displacement is more significant; considering the roof displacement of the short side (more flexible) under seismic loads, and asynchronous vibration modes, it can reach $100 \mathrm{~mm}$. The fixation of the steel plate to the $\mathrm{RC}$ elements is hypothesised from the façade plane with bolts chemically anchored to the RC. Particular attention on this connection must be paid for a realistic application. It is in fact important to have a reliable level of knowledge of the structural existing elements and materials in order to rely on chemical fixations. Additionally, a careful evaluation of the extra loads applied on the columns must be done. Depending on the existing elements, the steel plate may be connected to a steel reinforcing jacketing of the external RC columns to avoid local collapses. In order to transfer compressive loads between the RC frames and the CLT walls and so avoiding instability in the bars, hardwood components are provided in-between the steel connectors.

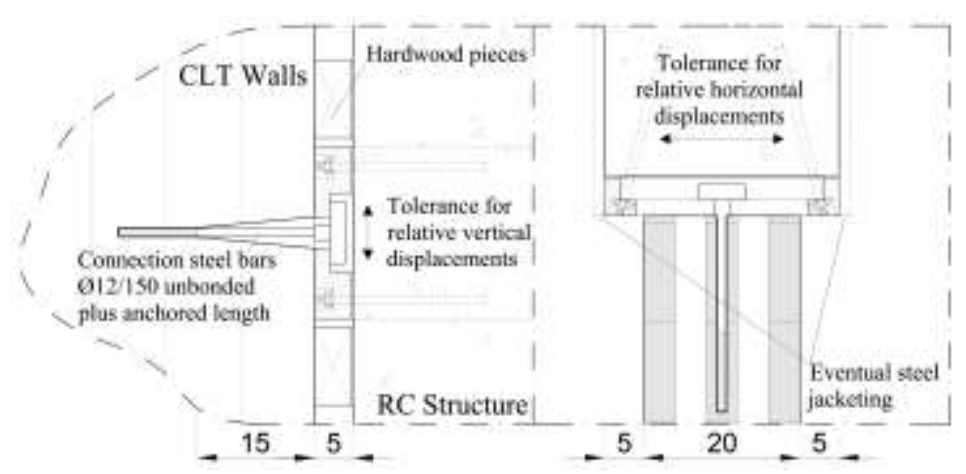

Fig. 11 Sketches of the vertical distributed connection between CLT walls and RC vertical structural elements 
During the installation procedure the steel bars could be already fixed to the CLT walls and arrive at the construction site with the steel plates in position (hanging from the chemical anchored steel rebars) for the fixation to the RC elements.

\section{FINITE ELEMENT MODEL}

A numerical model was developed with the finite element software ETABS (CSI 2018) both for the existing RC structure alone (initial state - IS) and for the combined solution with the CLT external structure (project state - PS). Through linear dynamic (modal response spectrum) and non-linear static (pushover) analyses, it was subsequently possible to assess the seismic improvement.

\subsection{INITIAL STATE - EXISTING STRUCTURE}

The existing moment-resisting RC structure is developed based on the existing case study of Brasov and located in the same area. The structure consists of five floors of $2.6 \mathrm{~m}$ height each with a total plan size of 28 $\mathrm{x} 15 \mathrm{~m}$ measured from the barycentric axes of the frames. The horizontal structures are made of $120 \mathrm{~mm}$ thick concrete slabs that can be considered as diaphragm constraints transferring the vertical loads in both the main directions. The beams have different heights depending on the spans, and a width that corresponds to the side of the columns. These vertical elements are $350 \times 350 \mathrm{~mm}$ at the ground floor and $300 \times 300 \mathrm{~mm}$ for the remaining storeys. The spans between columns are following the morphology of the reference Brasov structure but adapting the dimensions to the different structural system. Along the longitudinal direction $(\mathrm{X})$ the frame presents 7 spans of $4 \mathrm{~m}$, while in the transversal direction (Y) two spans of $6 \mathrm{~m}$ are interrupted by a single $3 \mathrm{~m}$ span (see Figure 12). The dimensions of the structural elements and the amount of reinforcement are designed based exclusively on vertical loads, with stresses coming from the ultimate limit state combination as defined by the Eurocodes (CEN 2002; 2004a). The cross-sectional dimension of the structural elements together with the reinforcement content are indicated in Table 5. In addition to dead loads, including weights coming from the various masonry infill and partition walls, live loads referred to residential building were considered.

Table 5 Cross-sectional dimensions of beams (B) and columns (C) are indicated in the table together with the relative reinforcement content and spanning lengths

\begin{tabular}{ccccc}
\hline Cross-section & Span & \multicolumn{2}{c}{ Long. Rebar } & Trans. Rebar \\
\hline mm & $\mathrm{m}$ & Top & Bottom & $\phi /$ step (mm) \\
\hline C 350x350 & 2.6 & $3 \phi 18$ & $3 \phi 18$ & $\phi 8 / 200$ \\
\hline C 300x300 & 2.6 & $2 \phi 18$ & $2 \phi 18$ & $\phi 8 / 200$ \\
\hline B 350x400 & 4 & $3 \phi 14$ & $3 \phi 14$ & $\phi 8 / 200$ \\
\hline B 350x400 & 6 & $2 \phi 18$ & $3 \phi 14$ & $\phi 8 / 200$ \\
\hline B 350x250 & 3 & $3 \phi 14$ & $3 \phi 14$ & $\phi 8 / 200$ \\
\hline B 350x300 & 4 & $3 \phi 14$ & $3 \phi 14$ & $\phi 8 / 200$ \\
\hline B 300x400 & 4 & $3 \phi 14$ & $3 \phi 14$ & $\phi 8 / 200$ \\
\hline B 300x400 & 6 & $2 \phi 18$ & $3 \phi 14$ & $\phi 8 / 200$ \\
\hline
\end{tabular}




\begin{tabular}{lllll}
\hline \multicolumn{5}{c}{$1 \phi 14$} \\
\hline B 300x250 & 3 & $2 \phi 14$ & $2 \phi 14$ & $\phi 8 / 200$ \\
\hline B 300x300 & 4 & $3 \phi 14$ & $2 \phi 14$ & $\phi 8 / 200$ \\
\hline
\end{tabular}

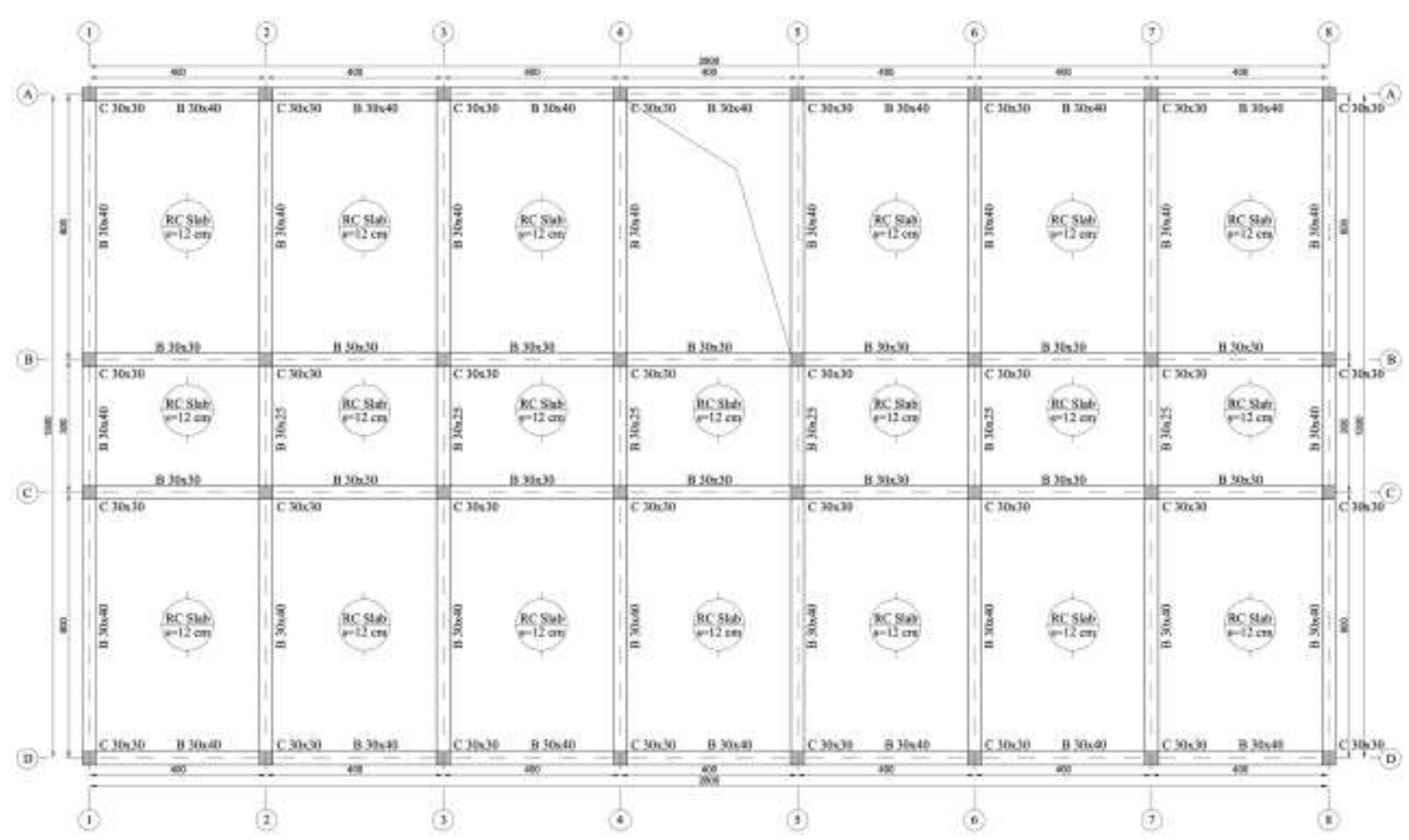

Fig. 12 Typical horizontal cross section of the moment-resisting structure. Due to the symmetry of the structure only half of the planimetry is shown. Cross-sectional dimensions of beams (B) and columns (C) are indicated in $\mathrm{cm}$ together with spans

As regards of the materials, concrete class C20/25 $\left(f_{c k, c y l}=20 \mathrm{MPa}\right)$ and steel grade PC52 $\left(f_{y k} \geq 355 \mathrm{MPa}\right)$ were used with reference to the technical assessment report provided by the municipality of Brasov in the framework of Pro-GET-onE (Maslaev Consulting 2015).

A three-dimensional model was created to carry out the seismic analyses (Figure 13). Fixed joints were introduced at the foundation level as external restrains and diaphragm semi-rigid constraints were introduced for all the joints belonging to the floor levels, defined as membranes of $120 \mathrm{~mm}$ in RC. Beams and columns were modelled as nonlinear frame elements with lumped plasticity by defining plastic hinges at both ends of the elements. The hinge properties follow the formulas reported in the Annex A of the Eurocode 8-Part 3 (CEN 2005) for ductile mechanisms and can identify the performance levels for each step of the non-linear static analysis (see paragraph 4). The behaviour of these hinges is depending on the cross-section of the element, the material properties, the longitudinal and transversal steel reinforcements, and the axial loads calculated with a quasi-static combination of vertical loads. ETABS provides default-hinge properties, PMM (combined flexural and axial loads) hinges for columns and M3 (only flexural loads) hinges for beams were assigned. In order to take into account brittle failures on the same elements, force-controlled hinges were placed in the middle of each column and at the ends of each beam (V2 for beams and V2-V3 for columns). The shear strength, which is the maximum allowable force for these hinges, is calculated with reference to the paragraph 6.2.3 of (CEN 2004a). 


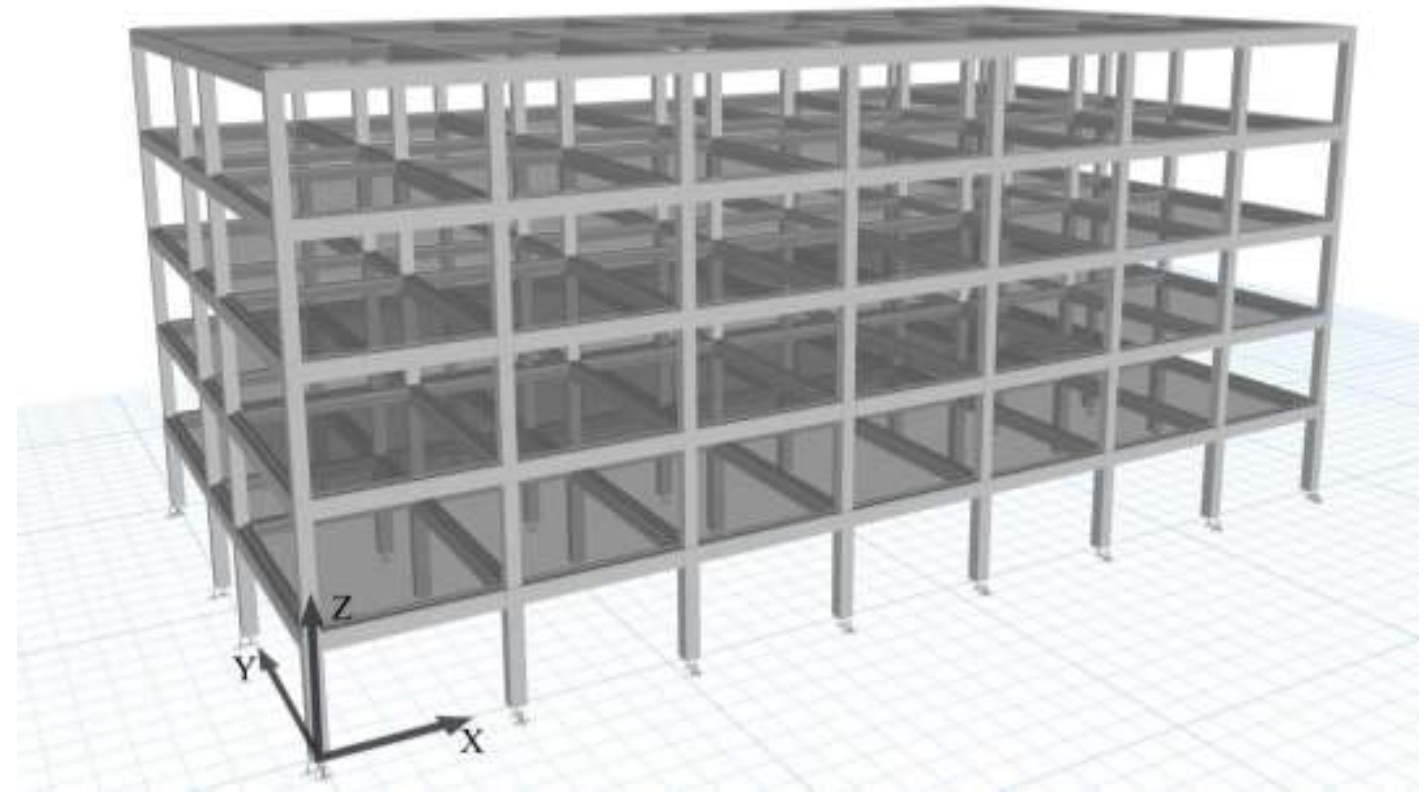

Fig. 13 Finite element model of the initial state (RC moment-resisting structure)

As unique difference between the non-linear model and the linear one a consideration was made on the concrete cracking. On this purpose, in the linear model a property modifier is reducing beam and column shear and flexural stiffnesses of 50\% as indicated in (CEN 2004c).

\subsection{PROJECT STATE - CLT STRUCTURE}

As mentioned above the CLT walls are placed in the same plane of the RC frames and are increasing the performance against horizontal loads acting in-plane to the walls. In the longitudinal direction, the two systems remain independent. Therefore, to obtain an improvement in both the main directions, the CLT external structure must be provided on the entire perimeter as shown in Figure 2.

In the numerical model the CLT panels are realised with shell layered elements that provides crossed layers of the implemented timber orthotropic material (CLT made of birch and spruce as defined in Table 1). The correct behaviour of the CLT panels is checked based on (Aondio et al. 2020a; Aondio et al. 2020b). Basic FEM models were created to verify the possibility of using shell layered elements as CLT panels. The deformations due to out-of-plane loads, the torsional stiffness, the stability with second order effects and the in-plane shear stiffness were carefully compared with hand-calculations. All these numerical tests gave good results with variations in displacements below the $2 \%$ apart for the deformations due to out-of-plane loads. In fact, the shell layered elements follow a Kirchhoff formulation and, as stated in (Aondio et al. 2020a), do not consider the shear rigidity $S_{\mathrm{xz}}$ with an error that decreases as the length of the element increases (higher slenderness). Therefore, to take into account the shear deformation, a reduction of the modulus of elasticity is applied at the orthotropic material imputed for the various layers depending on the static scheme of each considered element (see Table 6) as indicated in (Aondio et al. 2020a).

$$
B_{e f f, x}=\frac{B_{x}}{1+\frac{B_{x} \cdot \pi^{2}}{S_{x z} \cdot l^{2}}} \rightarrow R_{F}=\frac{B_{e f f, x}}{B_{x}}-\text { reduction factor }
$$

Table 6 Reduction factors imputed on the orthotropic material used in the software to describe the timber layers in the CLT elements. The static schemes used do not take into account the rotational stiffness of the PT-connections in the cases of horizontal slabs and walls in the levels from 1 to 5 


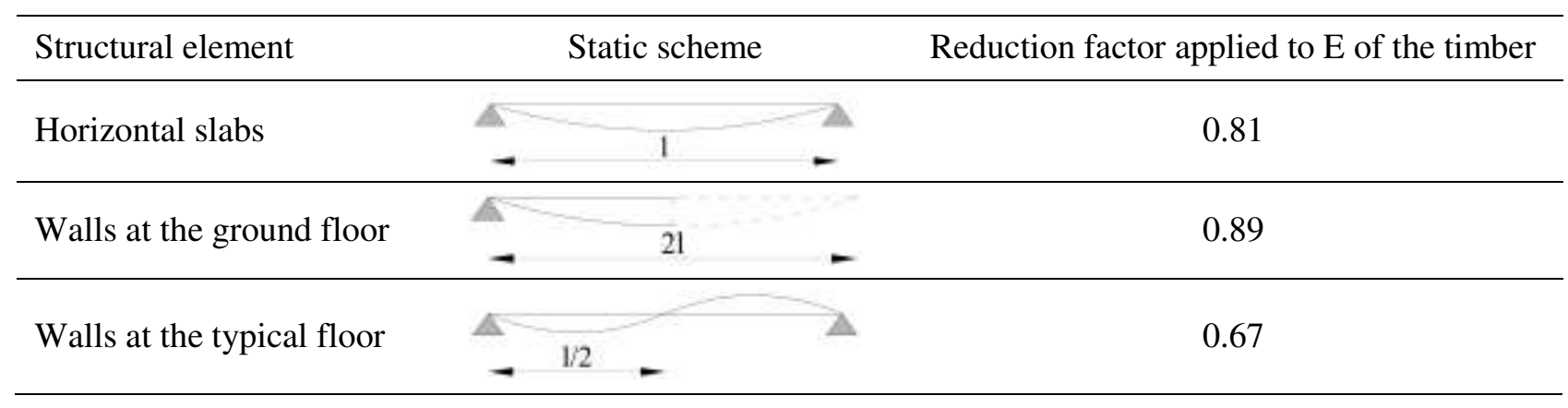

Multi-linear springs with linear stiffness and relative linear and non-linear behavioural laws are implemented in the model to represent the various connectors involved (PT-CLT connections, hold-downs, angular brackets, steel fixating rods) and the activated friction. The PT-CLT connection was implemented in the FEM with rotational springs (see Figure 14a) characterised by the behavioural law (moment-rotation) illustrated in Figure 8 and a linear stiffness calculated considering the angular coefficient of the line in the elastic phase (see Table 7). Since shear deformations were relevant only for horizontal loads, two models were developed independently with PT-CLT connections set respectively for vertical loads (ultimate limit state, ULS and serviceability limit state, SLS) and horizontal loads (significant damage limit state, LS-SD and damage limitation limit state, LS-DL). The $2 \mathrm{~m}$ depth shell-layered elements, representing the CLT structural elements, were regularly divided in four parts creating five joints at the edges. The stiffness of each spring (five for each PT-CLT-connection) is determined considering double of the depth of the single $1 \mathrm{~m}$ system (multiplying by 2 ) and then assigning $1 / 5^{\text {th }}$ to each spring located at the connecting side. In the same way the moment-rotation behaviour is distributed along the rotational springs as shown in Figure 14b.

The connection with the existing structure is realised in FEM with a multi-linear spring with a linear stiffness as reported in Table 8 and an axial linear and non-linear behaviour as represented in Figure 14d. Twenty connectors are provided along the height of the entire structure (four per storey) and connected to the joints of the CLT-shell elements and to rigid links representing the thickness of the RC columns (Figure 14c).

Table 7 Rotational effective elastic stiffness of the PT-CLT connections referred to $1 \mathrm{~m}$ CLT structure

\begin{tabular}{cccc}
\hline Value & Units & Inner PT-connection & Outer PT-connection \\
\hline$k_{\text {vert.loads }}$ & $\mathrm{kNm} / \mathrm{rad}$ & $117^{\prime} 000$ & $23^{\prime} 565$ \\
\hline$k_{\text {horiz.loads }}$ & $\mathrm{kNm} / \mathrm{rad}$ & $13^{\prime} 102$ & $23^{\prime} 565$ \\
\hline
\end{tabular}

Table 8 Values of the elastic stiffness of the steel connecting rods ( $\phi 12)$, single and double angular brackets (BMF116)(Dujic et al. 2010) and hold downs (HTT22)(Dujic et al. 2010); friction is neglected in linear analyses

\begin{tabular}{cccccc}
\hline Connector & Units & Tensile strain & Shear strain & Tensile strain & Shear strain \\
\hline & & \multicolumn{2}{c}{ Single Connector (one side) } & Double Connector (two sides) \\
\hline$k_{\phi 12}$ & $\mathrm{kN} / \mathrm{m}$ & $158^{\prime} 336$ & - & - & - \\
\hline$k_{B M F 116}$ & $\mathrm{kN} / \mathrm{m}$ & 5000 & 8000 & $10^{\prime} 000$ & $16^{\prime} 000$ \\
\hline$k_{\text {HTT22 }}$ & $\mathrm{kN} / \mathrm{m}$ & $11^{\prime} 250$ & - & $22^{\prime} 500$ & - \\
\hline
\end{tabular}


a)

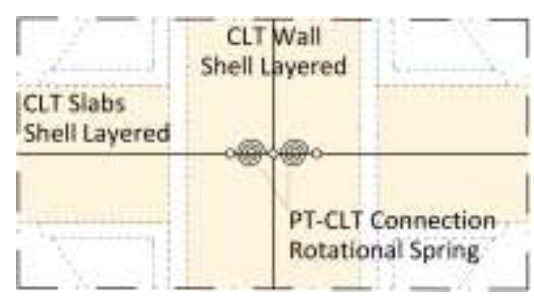

c)

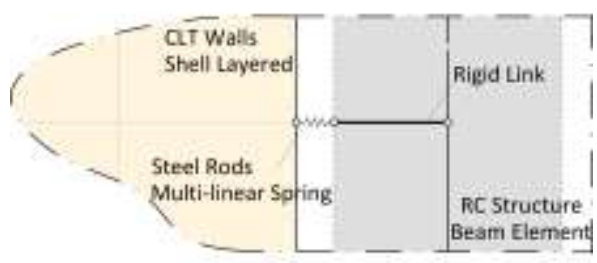

b)
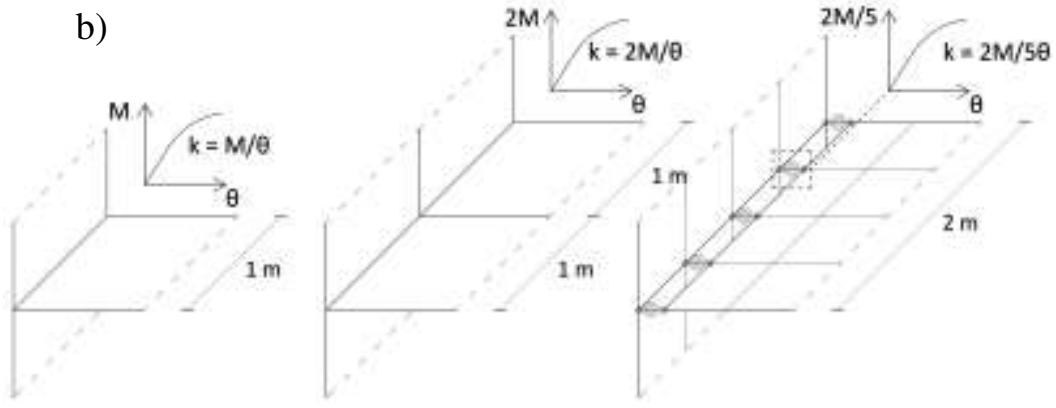

d)

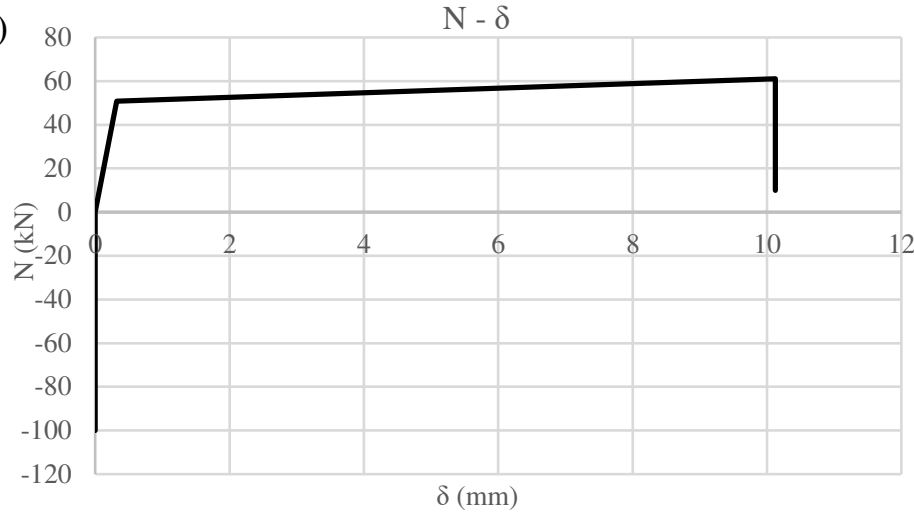

Fig. 14 a) FEM-scheme of the PT-CLT inner connection; b) Distribution of the PT-CLT connection in multilinear rotational springs; c) FEM-scheme of the steel fixating rod connection between RC columns and CLT walls; d) Envelope and load bearing capacity of the steel rods applied as axial connectors. While the tensile behaviour is characterised by the tensile capacity of the $\phi 12 / 150$ rods, the compressive transfer is guaranteed by the hardwood pieces

Regarding the foundation connectors, a series of rigid links is provided at the final side of the shell layered element to adjust the shell subdivisions with the multi-linear springs representing angular brackets, holddowns, and friction (see Figure 15). While angular brackets (BMF116) are characterised by behavioural laws describing deformations under axial and shear loads, the hold-downs (HTT22) only present the first component. To simplify the model, the springs representing the hold-downs also contain the friction contribution (divided by the number of springs considered along the length). The envelope and load bearing capacity of these connectors are shown in Figures 16 and 17 for single connector with reference to (Dujic et al. 2010).

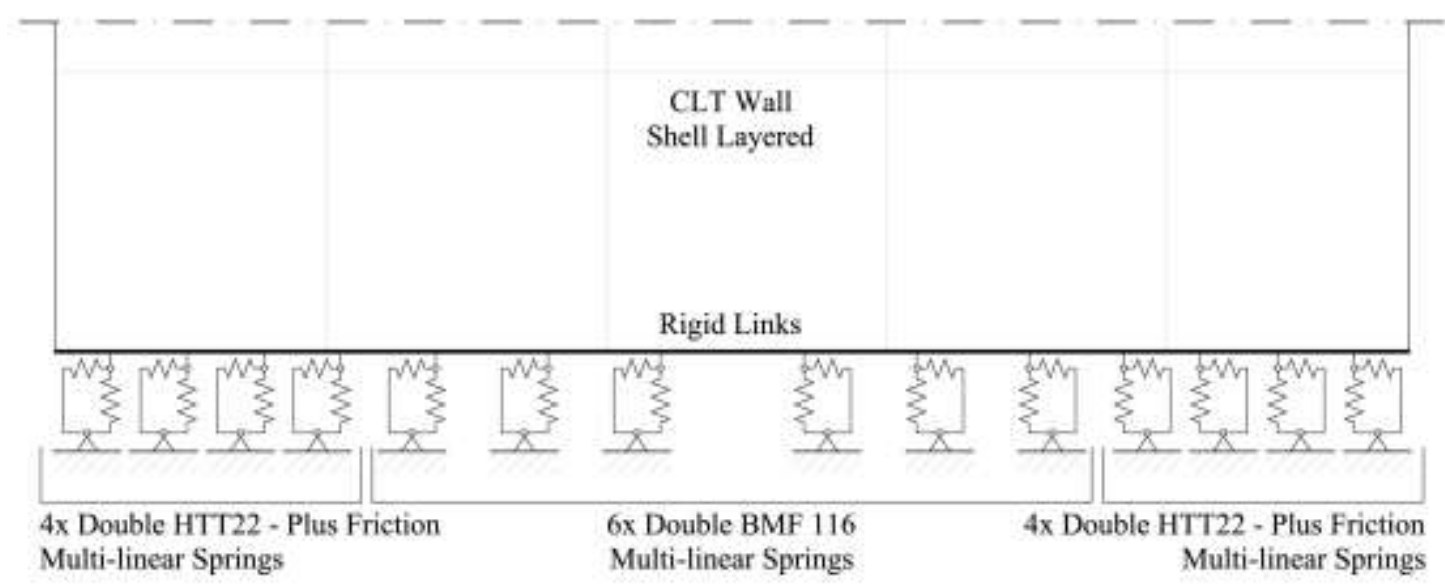

Fig. 15 FEM-scheme of the connectors provided at the base of the shell layered CLT wall on one side 

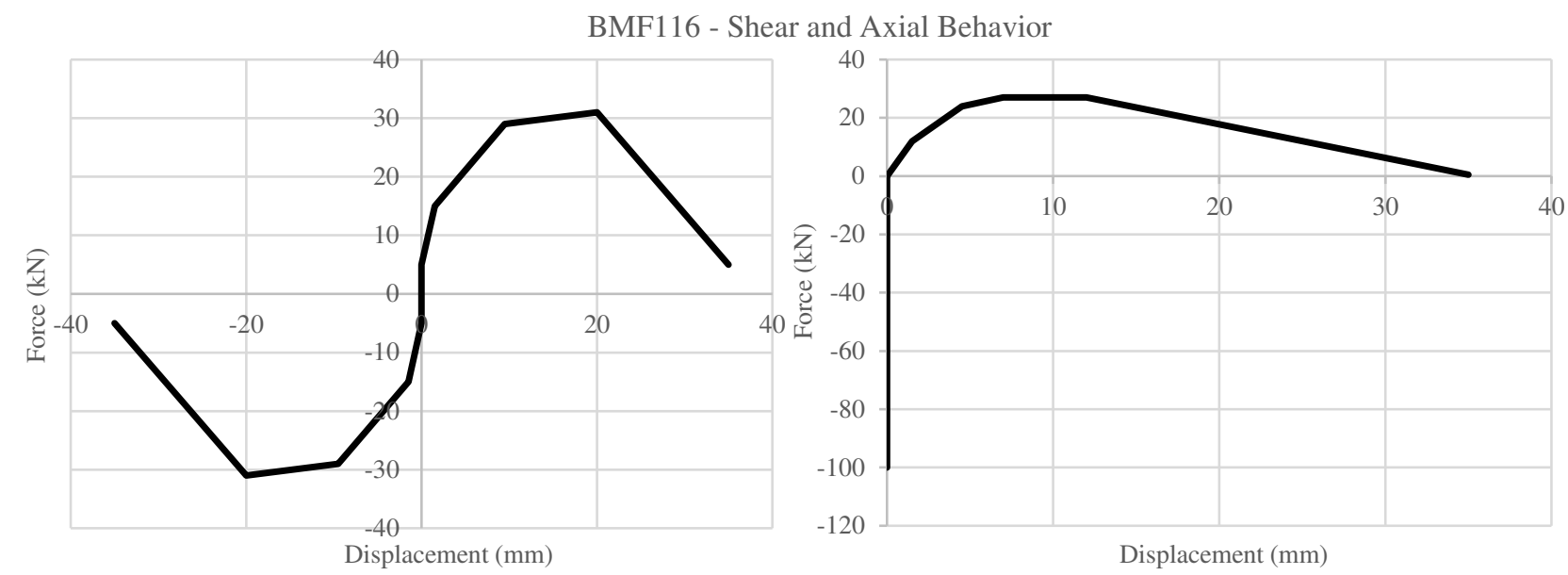

Fig. 16 Envelope and load bearing capacity of the shear anchor with 12 nails of $\phi 4$ / $60 \mathrm{~mm}$ when acting in shear (left graph) and with axial loads (right graph)(Dujic et al. 2010)

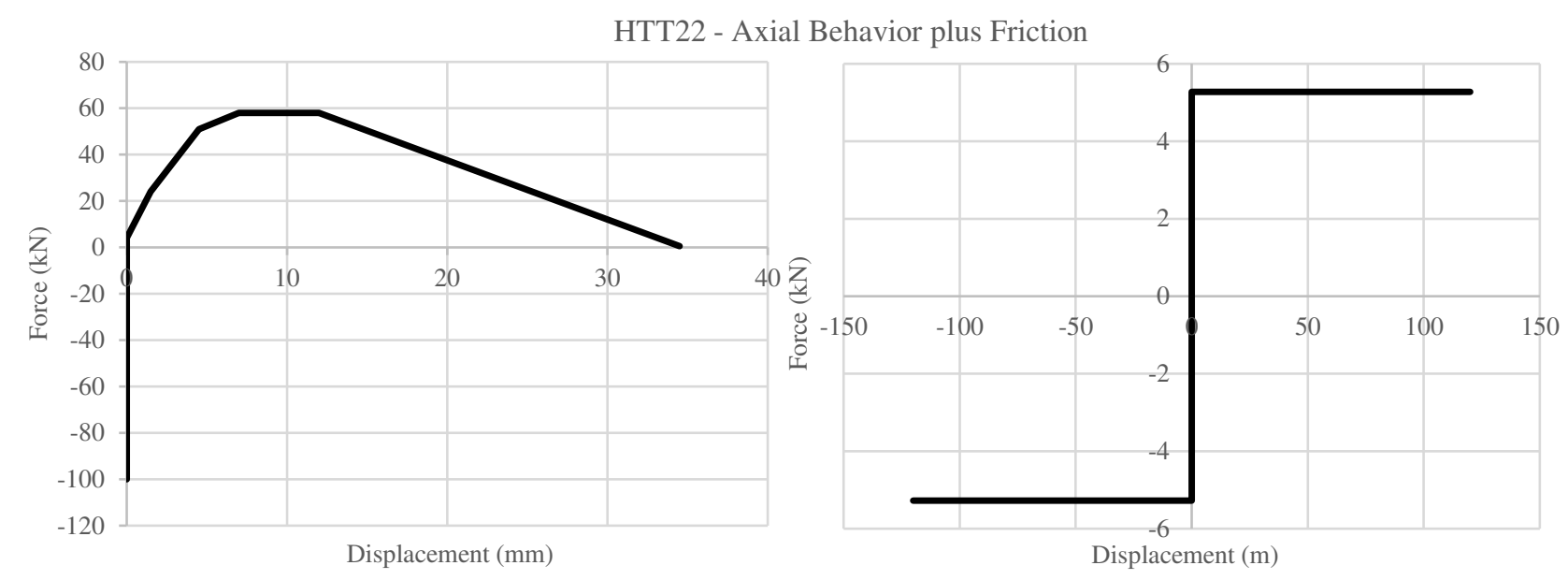

Fig. 17 Envelope and load bearing capacity of the hold-down with 22 nails of $\phi 4$ / $60 \mathrm{~mm}$ for preventing up-lifting (left graph) and $1 / 8$ of the friction contribution

In the FEM, forces and linear stiffnesses of the connectors have been doubled because of a double number of connectors intended to be applied on both sides of the CLT walls.

It is important to mention that for the linear analyses the axial behaviour of the connectors cannot be represented correctly due to actual non-linear behaviour from tension to compression. Therefore, since the deformation in the model is twice the one of a real in-plane loaded CLT wall (considered as rigid body, see Figure 18), the axial linear stiffness of the connectors has been doubled. 


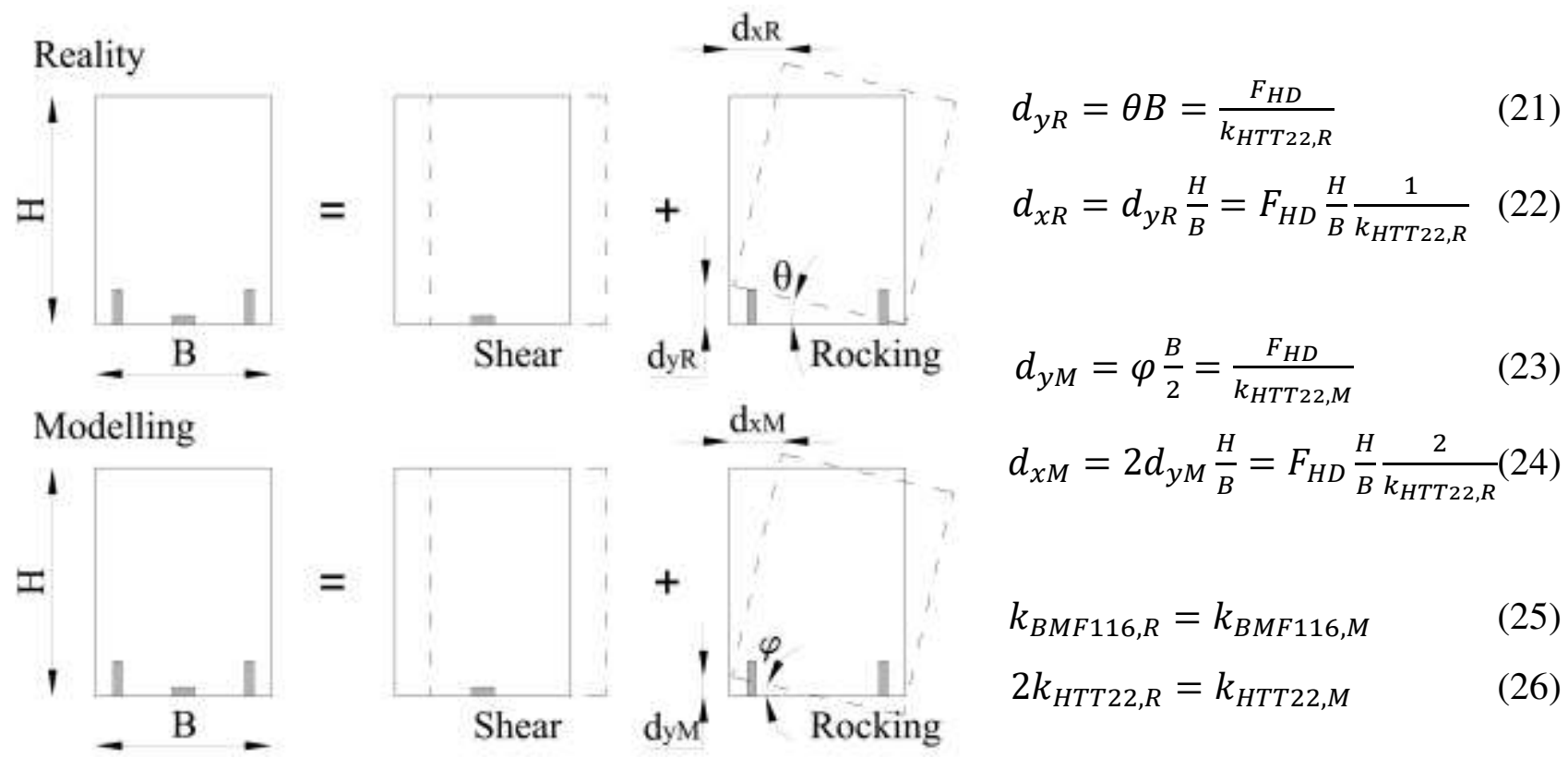

Fig. 18 Connector's stiffnesses, determination of the axial linear equivalent stiffness to use in the FEM

\section{SEISMIC ANALYSES}

Modal response spectrum dynamic linear analyses (RSAs) and static non-linear pushover analyses (SPOs) were carried out before and after the application of the timber-based addition on the basis of the provisions of the Eurocode 8 (CEN 2004c). While RSAs were used to design the new structural elements and connections, reporting the stresses affecting them in the different design load combinations (ULS, SLS and LS-SD), SPOs allowed to assess the seismic vulnerability before and after the structural strengthening, thus determining the obtained improvement.

A type 1 elastic response spectrum on ground type A was matched (see Figure 19) with the use of the database provided in (Giardini et al. 2014), characterised by a peak ground acceleration of $0.2 \mathrm{~g}$ with a return period of 475 years $\left(\mathrm{P}_{\mathrm{r}}=10 \%\right.$ in 50 years $)$, and then increased with respect to the soil factor $\mathrm{B}$ as indicated in the available technical report (Maslaev Consulting 2015). Based on the elastic response spectrum different design spectra were defined depending on the different q-factors, obtained with the SPOs (differentiated by directions and state of the project), and reported in Table 10. The design response spectrum for LS-SD was calculated by dividing the ordinates of the elastic response spectrum by the q-factor. The latter was defined for this case study, following the approach presented in (Maheri et al. 2003). With reference to Table 10, the following values were obtained from the pushover analyses based on the maximum displacement set to the LS-SD (formation of the first plastic hinges beyond the limit state of significant damage).

- $R_{\mu}$ - ductility reduction factor, defined as the ratio of the elastic design force $\left(V_{e}\right)$ to the yield strength level $\left(V_{y}\right)$, reflecting the energy dissipation capacity of the system and coinciding with the ductility $(\mu)$ measured as the ratio of the displacement capacity $\left(\Delta_{\max }\right)$ at the LS-SD to the displacement linked to the yield point and the idealised elastic-perfectly plastic response curve $\left(\Delta_{y}\right)$ (Maheri et al. 2003).

- $R_{S}$ - the overstrength factor, defined as the idealised structural yield level $\left(V_{y}\right)$ and the first actual significant yield level $\left(V_{S}\right)$, corresponding to the first hinge beyond the LS-DL (limit state of damage limitation; similar to what defined by the Eurocodes), representing the reserve strength that exists between the two points (Maheri et al. 2003). 
The behaviour factor $(\mathrm{q})$ was finally evaluated as product between the ductility reduction factor $\left(R_{\mu}\right)$ and the overstrength factor $\left(R_{S}\right)$. The minimum q-factors were selected among the analyses performed in both directions. For the initial state 2.90 and 2.67 were used for longitudinal and transversal direction respectively, while a value of 1.50 was always imputed for the verification of brittle mechanisms.

The stresses belonging to the RSAs were combined with a quasi-permanent combination of vertical loads and verified for each CLT panel (slabs and walls) as indicated in (CEN 2004b; Aondio et al. 2020b). Furthermore, also ULS and SLS combinations were checked using, as mentioned in previous paragraphs, two different models based on different rotation springs representing the PT-CLT connections. For the verifications, the capacity of the PT-CLT connection was considered with losses in the tendon force about $30 \%$ as indicated in (Gräfe et al. 2018; Wanninger 2015; Wanninger et al. 2015).

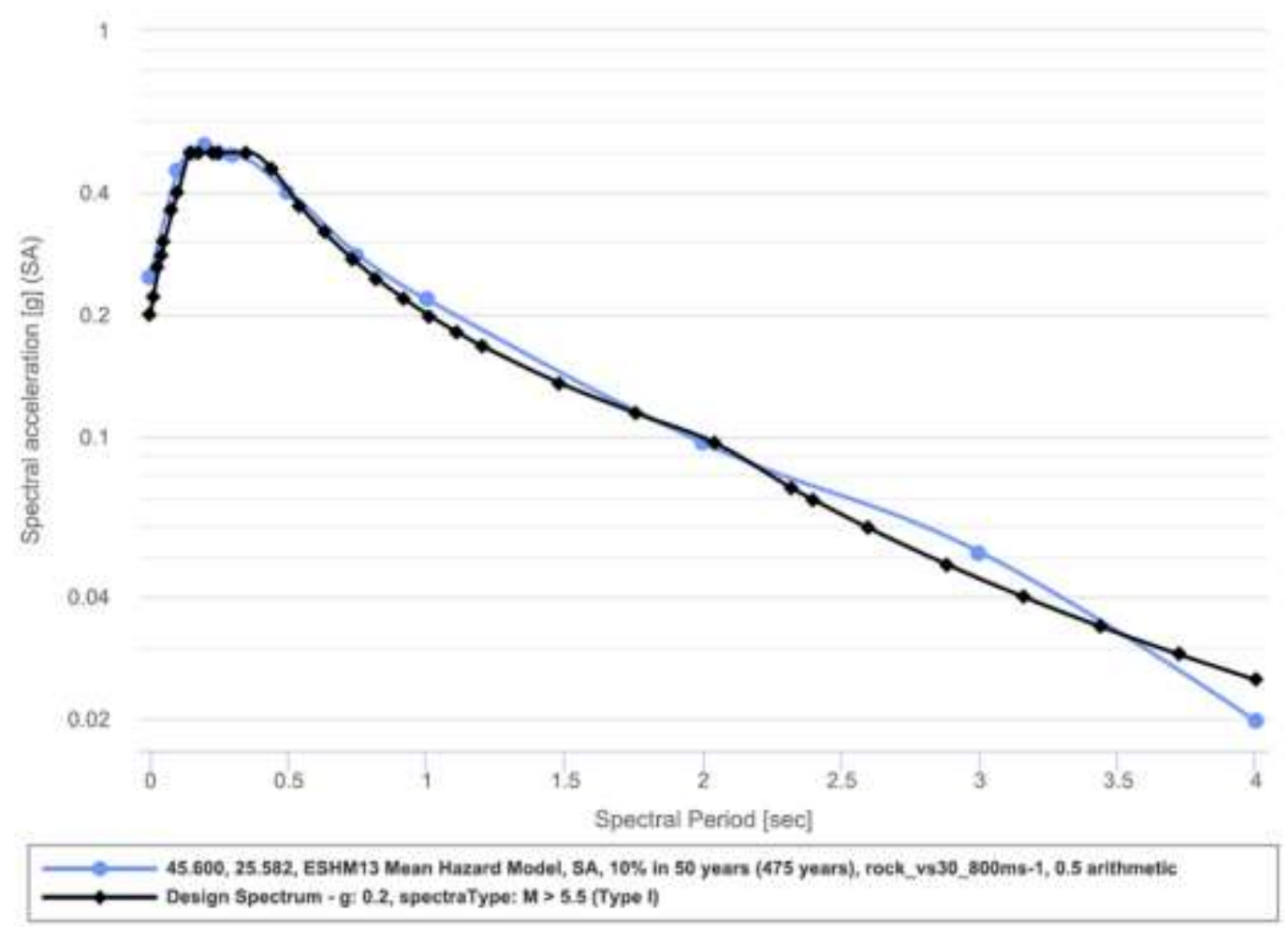

Fig. 19 Registered elastic response spectrum of Brasov (45.600-25.582) with matching EU8 spectrum (CEN 2004c; Giardini et al. 2014), www.efehr.org/Documentation/licenses-copyright

In the same way, all the forces affecting the connectors were checked (hold-downs, angular brackets, PT-CLT connections and steel bars), resulting in the fulfilment of the requirements. The only exception was related to some external hold-downs that would have required an increased number of nails with a consequent increased stiffness and an additional iteration of the design not included in this study. In Table 9 the maximum forces affecting the connectors are shown together with the strength capacity (both with 22 and 26 nails for the axial capacity of the hold-downs).

Table 9 Maximum forces obtained with the RSA at the LS-SD for the different components of the connectors: steel connecting rods ( $\phi 12)$, angular brackets (BMF116) and hold downs (HTT22); the capacities are also reported considering a $\mathrm{k}_{\mathrm{mod}}$ of 1.1 and $\mathrm{a} \gamma_{\mathrm{m}}$ of 1.3

\begin{tabular}{ccc}
\hline Value & Units & Maximum design force \\
\hline
\end{tabular}




\begin{tabular}{cccc}
\hline$N_{\phi 12}$ & $\mathrm{kN}$ & 55.00 & 61.07 \\
\hline$V_{\text {BMF116 }}$ & $\mathrm{kN}$ & 9.32 & 23.44 \\
\hline$N_{\text {BMF116 }}$ & $\mathrm{kN}$ & 7.98 & 21.62 \\
\hline$N_{\text {HTT22_22n }}$ & $\mathrm{kN}$ & 47.11 & 46.54 \\
\hline$N_{\text {HTT22_26n }}$ & $\mathrm{kN}$ & - & 55.00 \\
\hline
\end{tabular}

With the displacements obtained through the RSAs was possible to check the interstorey drift $\left(\mathrm{d}_{\mathrm{r}}\right)$ before and after the application of the timber strengthening solution for both the main directions following 4.4.3.2 of (CEN 2004c). As shown in Figure 20, the interstorey drifts of the centres of masses (CM, calculated on the existing building) resulted beyond the design requirements for the initial state and verified in the project solution. Resulting, in terms of capacity/demand ratios, in an improvement from $80 \%$ to $110 \%$.
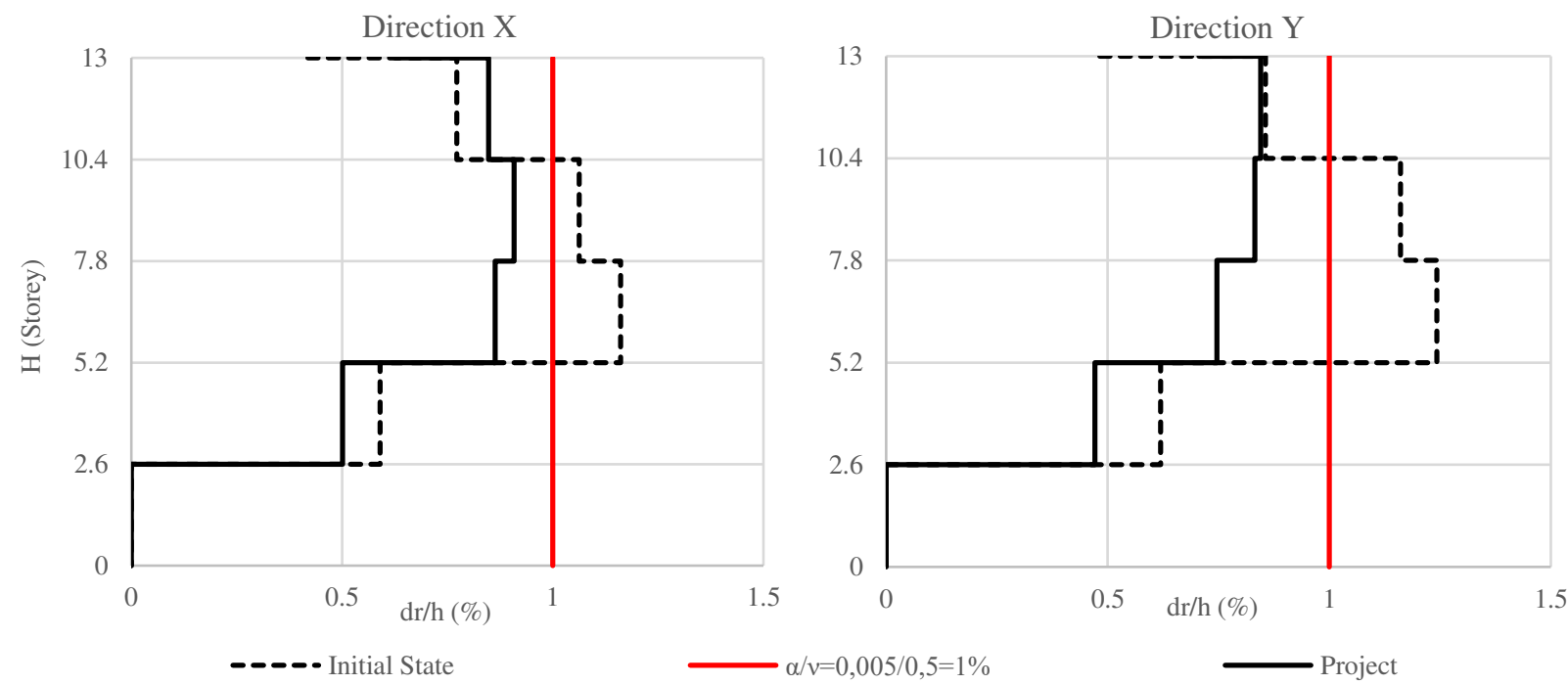

Fig. 20 Interstorey drift verification in both the main directions $(X, Y)$ before and after the project application

A force controlled static non-linear analysis based on the quasi-permanent vertical loads combination constitutes the starting point for the displacement-control pushover analyses (SPOs). The latter were performed, as required by the standards (CEN 2004c), in both direction, with positive and negative signs and using two different lateral load distributions: proportional to mass regardless of elevation and proportional to the lateral forces associated to the main vibrating modes. As results, capacity curves associating the total base shear acting at each loading step with the displacement of the control point, situated in the roof, are derived for the multi degree of freedom (MDOF) model. Below, in Figure 21, the capacity curves of the structure before and after the application of the timber addition are shown for both the main directions and with the weakest distribution of forces corresponding to the one proportional to modal shapes. 

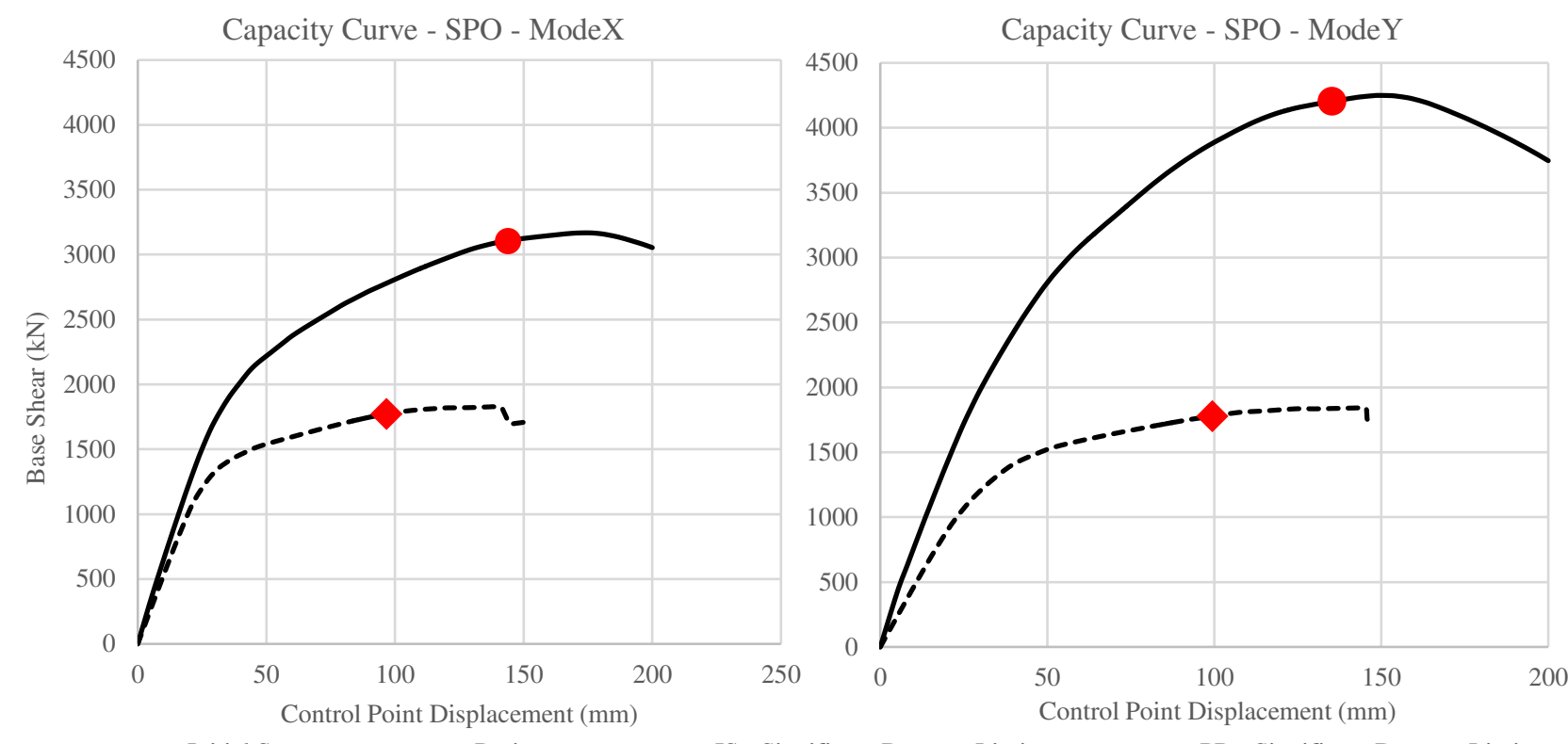

- - - Initial State — Project $\quad$ IS - Significant Damage Limit

- $\quad$ PR - Significant Damage Limit

Fig. 21 Capacity curves obtained with the SPO proportional to the lateral forces associated with the vibrating modes for both the main direction with before and after the project

It is possible to notice that the structure in the IS has a comparable behaviour in both directions, while due to the higher number of CLT walls applied along the longitudinal direction, the PS sees increased stiffness and capacity in transversal direction (Y). Furthermore, an increased displacement capacity is recorded as a consequence of the reduction of shear loads concentrated in the lower storeys.

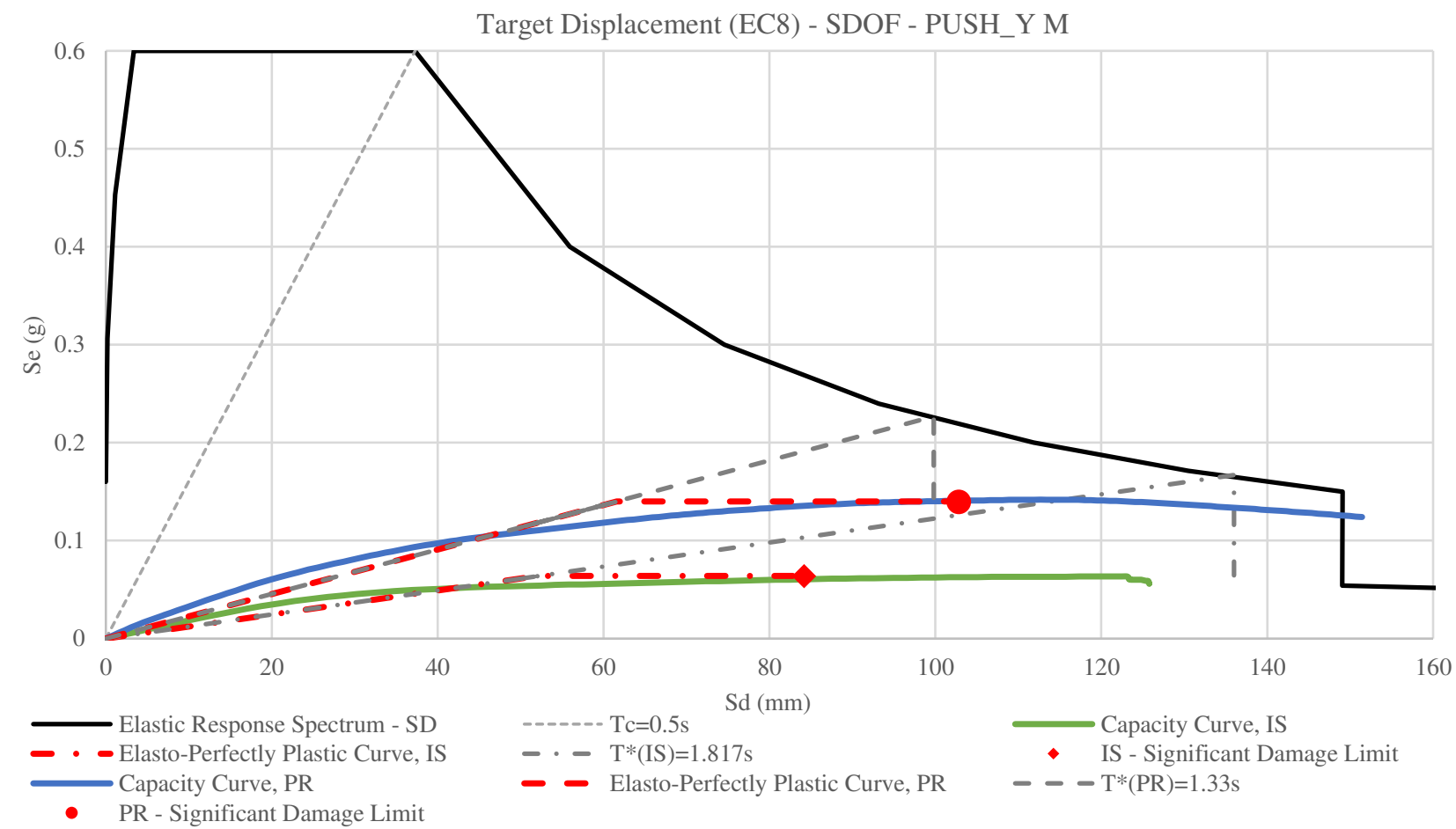

Fig. 22 Pseudo-acceleration and displacement elastic response spectrum $(0.2 \mathrm{~g})$, SDOF capacity curves with relative elasto-perfectly plastic curves and indicating displacement capacities, period values; through $\mathrm{T}^{*}$ and the elastic response spectrum the demanded displacements are also defined 
Finally, by using the target displacement verification (TDV) as defined in the Annex B of (CEN 2004c), the displacement capacity is evaluated for which the performance level of significant damage limit state was exceeded for the elements of the existing RC structure. The target displacement is found with the scaled capacity curves representing the equivalent single degree of freedom (SDOF) system and the elastic response spectrum of the site for the LS-SD. In Figure 22 a comparison between IS and PS is shown, displaying the capacity and demand values for the modal distribution of forces in transversal directions $\mathrm{Y}$ (positive sign).

Considering the elastic response spectrum introduced above, it was possible to evaluate the ratio between capacity and demand for all the assessed combination, obtaining an improvement that goes, in the weakest lateral load distribution (modal force distribution), from $62 \%$ to $101 \%$ in transversal direction (Y), and from $66 \%$ to $102 \%$ in the longitudinal one $(\mathrm{X})$.

The application of the timber external structure made it possible to increase the q-factors in both directions thanks to a better distribution of the damage along the height of the existing structure. In fact, the RC moment resisting frames present greater deformations in the lower storeys, implying a collapse that does not allow to exploit the full capacity of the RC structure (fib 2003; Feroldi et al. 2014). through the application of the timber-based exoskeleton, higher displacement capacities can be reached due to a modified deformed shape of the existing structure. The q-factor values passed from 2.90 to 3.63 for the longitudinal direction (X), and from 2.67 to 2.90 for the transverse direction $(\mathrm{Y})$.

Table 10 Target displacement verification for the significant damage performance level (LS-SD), $T_{R}=475$ years, $P_{V}=$ $10 \%$ in 50 years. Capacities and demands are expressed in $\mathrm{mm}$ of the control points and related base shear values (kN) for the analyses that regard the initial state (SPO) and the project (P-SPO). The letter M indicates the analyses done with lateral load distribution proportional to the main vibrating modes

\begin{tabular}{|c|c|c|c|c|c|c|}
\hline Analyses & $\begin{array}{c}\text { Capacity } \\
\text { Displ. (mm) } \\
\text { Shear }(\mathrm{kN})\end{array}$ & $\begin{array}{c}\text { Demand } \\
\text { Displ. }(\mathrm{mm}) \\
\text { Shear }(\mathrm{kN})\end{array}$ & $\mathrm{C} / \mathrm{D}(\%)$ & $\mathrm{R}_{\mu}$ & $\mathrm{R}_{\mathrm{S}}$ & q \\
\hline SPO X & $\begin{array}{l}90.1 \\
2185\end{array}$ & $\begin{array}{l}126.6 \\
2262\end{array}$ & 71 & 1.86 & 1.66 & 3.08 \\
\hline SPO -X & $\begin{array}{l}88.4 \\
2228\end{array}$ & $\begin{array}{l}124.6 \\
2307\end{array}$ & 71 & 1.84 & 1.74 & 3.19 \\
\hline SPO MX & $\begin{array}{l}96.7 \\
1773\end{array}$ & $\begin{array}{l}147.1 \\
1903\end{array}$ & 66 & 1.75 & 1.81 & 3.17 \\
\hline SPO M-X & $\begin{array}{l}99.4 \\
1778\end{array}$ & $\begin{array}{l}146.5 \\
1894\end{array}$ & 68 & 1.70 & 1.71 & 2.90 \\
\hline SPO Y & $\begin{array}{l}89.2 \\
2181\end{array}$ & $\begin{array}{l}136.9 \\
2275\end{array}$ & 65 & 1.67 & 1.63 & 2.72 \\
\hline SPO -Y & $\begin{array}{l}85.7 \\
2255\end{array}$ & $\begin{array}{l}133.5 \\
2352\end{array}$ & 64 & 1.63 & 1.64 & 2.67 \\
\hline SPO MY & $\begin{array}{c}99.4 \\
1778\end{array}$ & $\begin{array}{l}160.7 \\
2045\end{array}$ & 62 & 1.61 & 1.78 & 2.88 \\
\hline SPO M-Y & $\begin{array}{l}98.7 \\
1774\end{array}$ & $\begin{array}{l}159.3 \\
2015\end{array}$ & 62 & 1.61 & 1.78 & 2.88 \\
\hline
\end{tabular}




\begin{tabular}{|c|c|c|c|c|c|c|}
\hline \multirow{2}{*}{ P-SPO X } & 129.3 & 114.3 & \multirow{2}{*}{113} & \multirow{2}{*}{1.91} & \multirow{2}{*}{1.99} & \multirow{2}{*}{3.81} \\
\hline & 4227 & 4142 & & & & \\
\hline \multirow{2}{*}{ P-SPO -X } & 127.3 & 113.1 & \multirow{2}{*}{113} & \multirow{2}{*}{1.89} & \multirow{2}{*}{1.92} & \multirow{2}{*}{3.63} \\
\hline & 4255 & 4184 & & & & \\
\hline \multirow{2}{*}{ P-SPO MX } & 143.8 & 139.1 & \multirow{2}{*}{103} & \multirow{2}{*}{1.84} & \multirow{2}{*}{2.07} & \multirow{2}{*}{3.81} \\
\hline & 3109 & 3091 & & & & \\
\hline \multirow{2}{*}{ P-SPO M-X } & 142.5 & 139.7 & \multirow{2}{*}{102} & \multirow{2}{*}{1.83} & \multirow{2}{*}{2.07} & \multirow{2}{*}{3.79} \\
\hline & 3053 & 3042 & & & & \\
\hline \multirow{2}{*}{ P-SPO Y } & 119.9 & 110.4 & \multirow{2}{*}{109} & \multirow{2}{*}{1.67} & \multirow{2}{*}{1.74} & \multirow{2}{*}{2.90} \\
\hline & 5337 & 5273 & & & & \\
\hline \multirow{2}{*}{ P-SPO -Y } & 118.1 & 109.0 & \multirow{2}{*}{108} & \multirow{2}{*}{1.65} & \multirow{2}{*}{1.72} & \multirow{2}{*}{2.84} \\
\hline & 5438 & 5373 & & & & \\
\hline \multirow{2}{*}{ P-SPO MY } & 135.2 & 131.3 & \multirow{2}{*}{103} & \multirow{2}{*}{1.67} & \multirow{2}{*}{1.86} & \multirow{2}{*}{3.11} \\
\hline & 4204 & 4186 & & & & \\
\hline \multirow{2}{*}{ P-SPO M-Y } & 131.7 & 130.3 & \multirow{2}{*}{101} & \multirow{2}{*}{1.63} & 105 & 318 \\
\hline & 4192 & 4276 & & & נינ. & 3.10 \\
\hline
\end{tabular}

As shown in Table 10, all the seismic analyses resulted satisfied in the project solution. The effect of the application of the strengthening structure on the existing RC moment-resisting frame is shown is Figure 23, where a uniform shear deformation occurs over the entire height of the building; while previously, the first floors were primarily loaded.

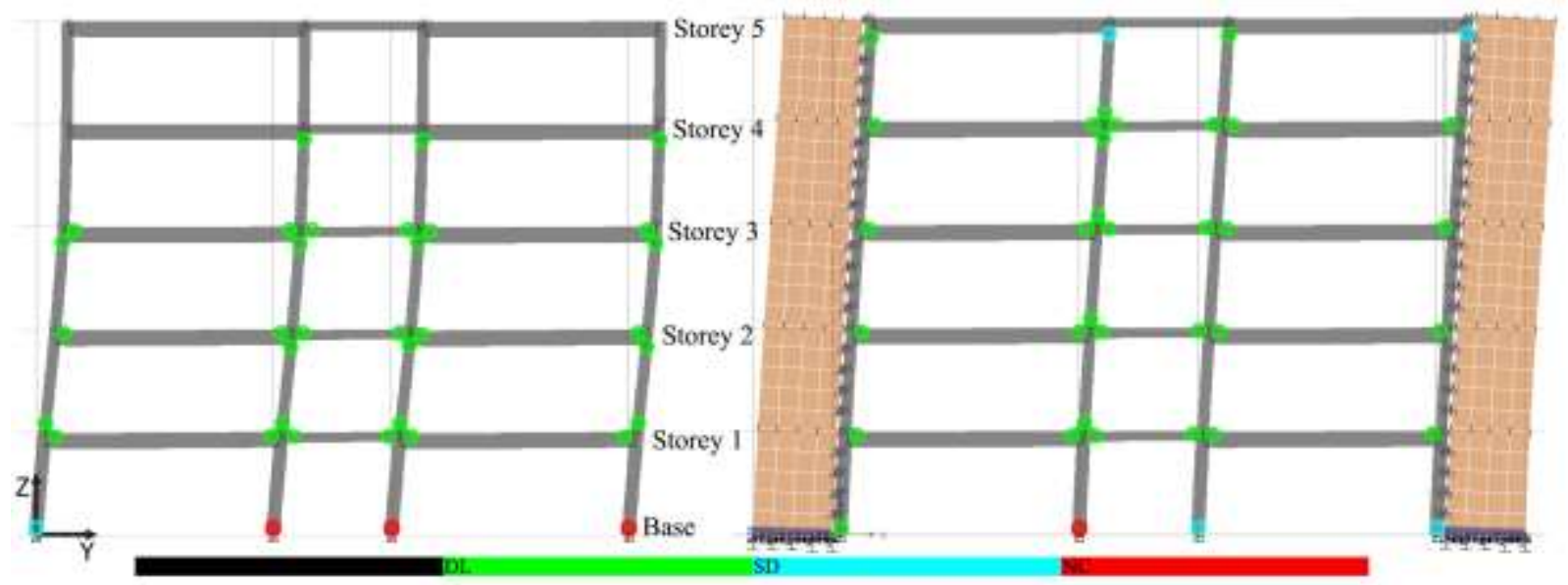

Fig. 23 Deformed shapes of the SPOs in transversal direction before and after the project application; the coloured dots represent the status of the plastic hinges

Finally, to measure the exploitation of the external structure the amounts of horizontal force taken by both the RC and the CLT structures were derived for the SPOs at the step of the LS-SD (Table 11) highlighting a margin of improvement of the system that could be explored in further steps by varying the base connection system. 
Table 11 Total horizontal forces registered at the step of the pushover analyses identifying the LS-SD, relative RC and CLT components with exploitation percentages of the external strengthening solution

\begin{tabular}{lcccc}
\hline Analyses & Total $(\mathrm{kN})$ & $\mathrm{RC}(\mathrm{kN})$ & $\mathrm{CLT}(\mathrm{kN})$ & $\%$ \\
\hline P-SPO X & 4145 & 2597 & 1548 & 37 \\
\hline P-SPO MX & 3108 & 2573 & 535 & 17 \\
\hline P-SPO Y & 5284 & 3292 & 1991 & 38 \\
\hline P-SPO MY & 4204 & 3253 & 951 & 23 \\
\hline
\end{tabular}

\section{TECHNOLOGICAL SOLUTIONS}

The technological solutions were designed based on the objectives of Pro-GET-onE, optimising the prefabrication of the components and the assembly procedure, guaranteeing efficient energy performance with a user-oriented approach.

Thanks to the use of prefabricated wooden elements and post-tensioned connections the assembly procedure of the structure is designed to be fast and practical. The steel connection plates constitute a useful temporary support for the slabs until application of the tension and the lightness of timber means reduction of time and costs.

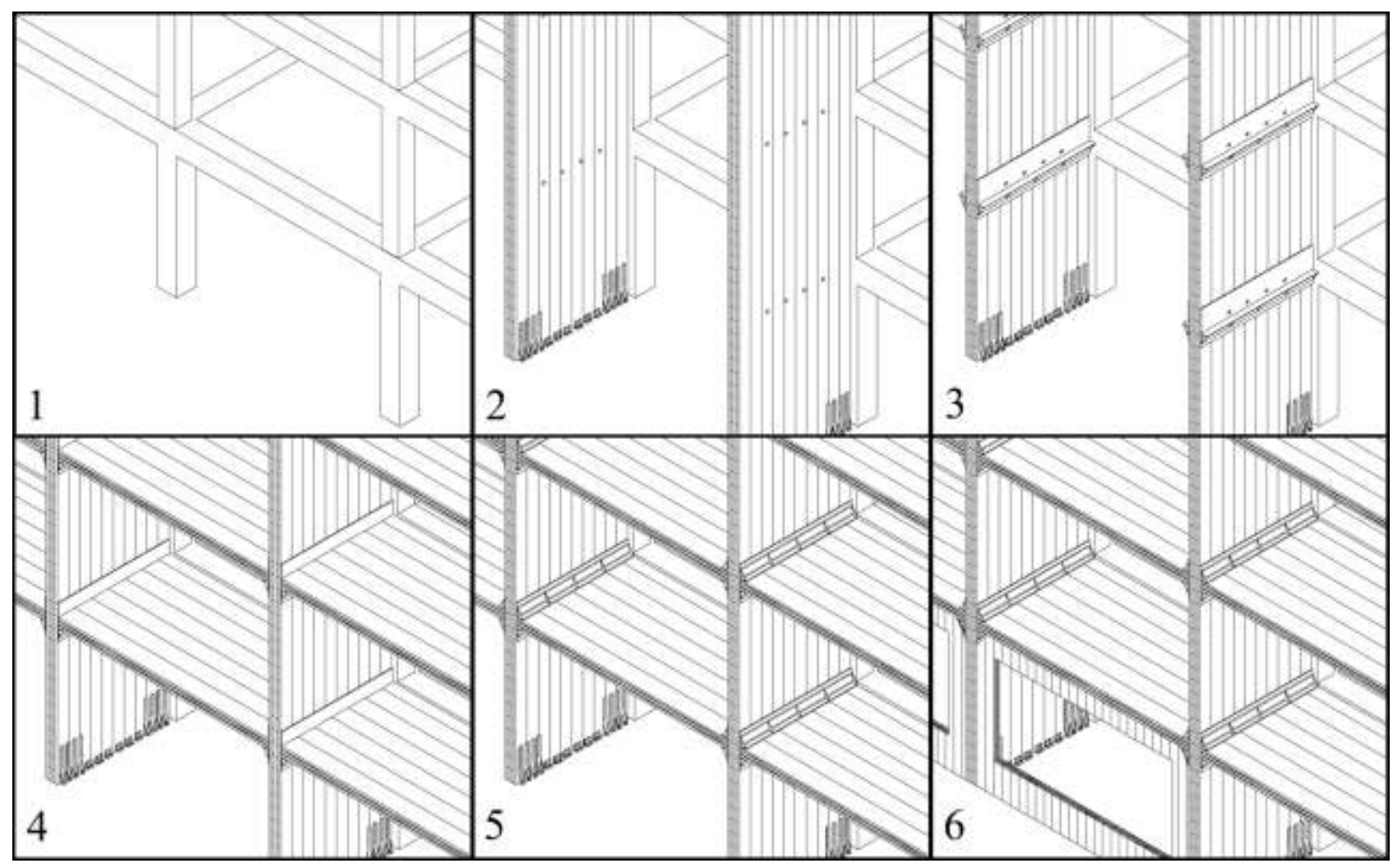

Fig. 24 Sketches representing the steps of the assembly procedure of the structure

In order, as shown in Figure 24: 
- CLT walls are fixed to the foundations (suitably designed based on the morphology of the existing ones, design loads and soil condition);

- steel plates without the upper angle profile and providing steel pipes as shear keys are inserted in specific holes in the CLT walls;

- horizontal CLT slabs are lifted on top of the steel L-shaped profiles;

- cables are inserted and the steel composite plate closed with the upper L-profile;

- the entire system is tensioned and the CLT panels at the ground floor are installed.

It is important to underline the disruption that could be generated during the construction of the foundations and the application of the connectors to the existing RC columns that could be related to a local strengthening.

Subsequently three architectural solutions are provided in direct collaboration with the CLT panels, extra-room (left drawing in Figure 25), sunspace, and balcony (right drawing in Figure 25). For each solution, the design guarantees thermal conductivity performances (U-value) suitable for a nearly zero energy building (Table 12). Pre-assembled façade components are therefore provided: an external wooden frame insulated panel for the extra-room and a technical beam integrated with railings, stringcourse and gutter for balcony and sunspace. In the last two cases, the new envelope is provided on the existing surface and can be easily installed exploiting the external structure.
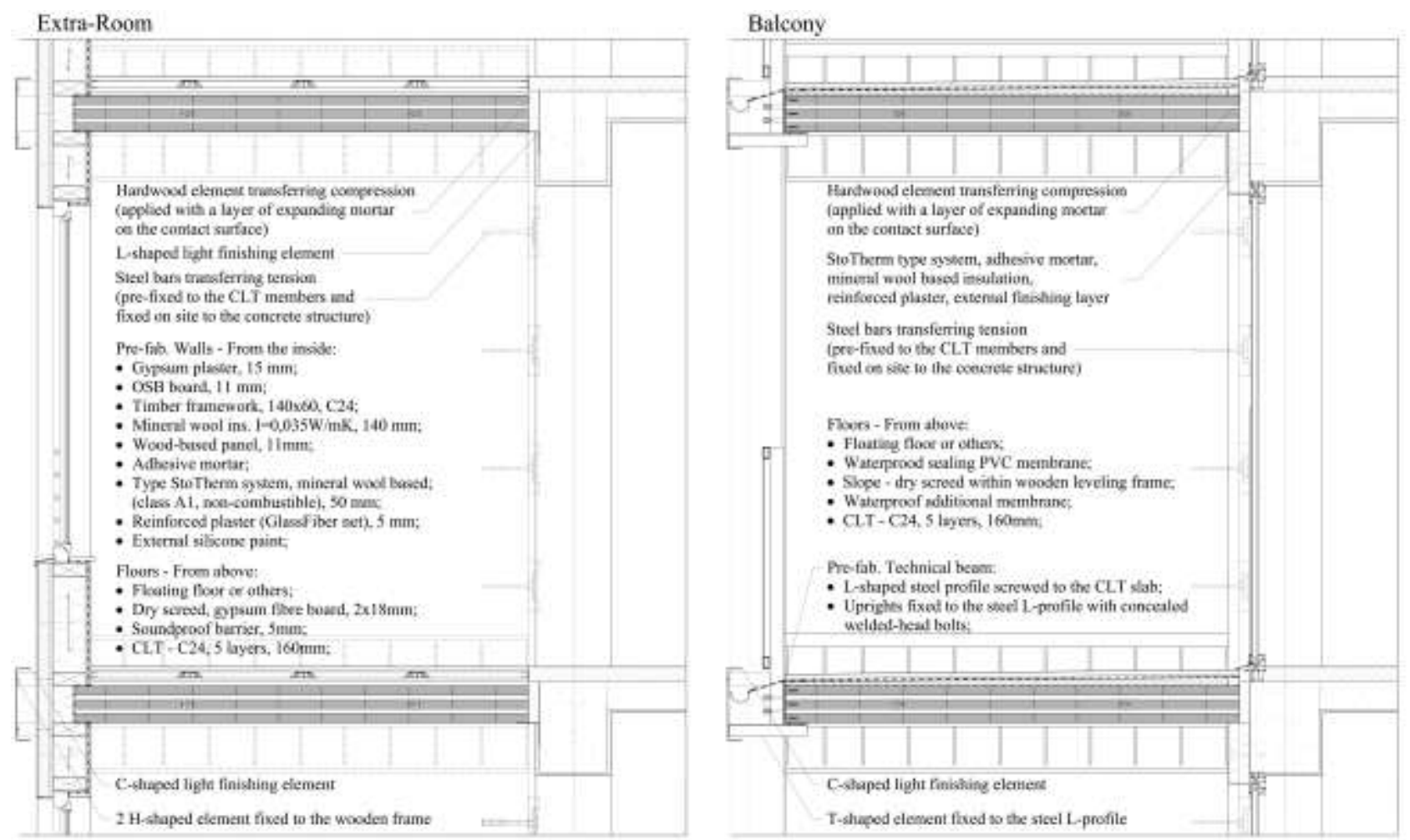

Fig. 25 On the left, the detail of the extra-room architectural solution provided within the external CLT strengthening structure. The prefabricated timber-based walls, providing window frames are easily inserted in between the CLT slabs and fixed to the main structure from the front; on the right, the balcony solution provides a technical prefabricated beam fixed to the front side of the CLT slabs

Table 12 Conductivity values associated to the external vertical partitions, designed to stay below the limit value of 0.24 $\mathrm{W} / \mathrm{m}^{2} \mathrm{~K}$

\begin{tabular}{lll}
\hline Walls & Positioning & $\mathrm{U}\left(\mathrm{W} / \mathrm{m}^{2} \mathrm{~K}\right)$ \\
\hline
\end{tabular}




\begin{tabular}{lll}
\hline Prefabricated timber-based walls & Extra-room & 0.196 \\
\hline Insulated RC frames & Balcony and Sunspace & 0.232 \\
\hline Insulated masonry infills & Balcony and Sunspace & 0.155 \\
\hline
\end{tabular}

It is important to mention the issues encountered in the adopted architectural renovation. The first regards the light reduction inside the existing units, that could be solved exploiting particular devices distributing the light from the frontal openings, such as light shelfs (Kontadakis et al. 2018). The second depends on the case study and its usable height. Characteristic of this particular case study, and of many similar residential building stocks, is the limited interstorey height, often defined in order to comply with the minimum usable height required by regulations by virtue of an optimised design. Consequently, where the height of the structural existing slabs (RC) is lower than the floor of the new addition (CLT), there will be a decrease in this height. To minimise this problem, it is therefore necessary to at least standardise the architectural solutions adopted for each façade, avoiding the installation of insulation at every additional floor, and closing off the heated cores either outside the addition (all extra-rooms) or on the edge of the existing façades (variable balcony or greenhouse). Finally, it is not always possible to overcome either building regulations or building restriction lines that could limit the surface possibly dedicated to extensions. These final requirements constitute mandatory boundaries and should therefore drive the choice of renovation typology at an early stage.

\section{CONCLUSIONS}

The contribution aims to introduce and describe a new integrated technology made out of timber engineering products (CLT panels) to ensure an energy and architectural retrofitting connected at the same time to a structural improvement. It has been proven to be able to answer the three main requirements of the European project Pro-GET-onE, providing an efficient and more sustainable alternative to the more established steel exoskeletons.

To exploit the geometry of the addition maintaining architectural freedom and speeding up the assembly procedure a PT connection between CLT panels is provided through an adaptation of the analytical method proposed in (Wanninger and Frangi 2014). Further mechanical tests on this topic are ongoing at the Technical University of Munich.

FEM of the structures were provided for the initial state and for the project solution to verify the new structural elements and to assess the seismic improvement obtained on a RC moment-resisting structure located in Brasov (Romania). The results of the analyses shown that this timber-based external structure could be comparable to a steel exoskeleton (Badini et al. 2019), even though the case study was different, satisfying the design displacement values associated to the performance level of significant damage. The ratio between capacity and demand for all the assessed combination resulted satisfied, obtaining an improvement that goes, considering the weakest lateral load distribution from $62 \%$ to $101 \%$ in transversal direction (Y), and from $66 \%$ to $102 \%$ in the longitudinal one $(\mathrm{X})$. Furthermore, verifications for the limit state of damage limitation, in terms of interstorey drifts got satisfied after the application of the integrated system. Resulting, in terms of capacity/demand ratios, in an improvement from $80 \%$ to $110 \%$.

However, the horizontal forces derived from the capacity curves at performance level of significant damage indicated that globally the CLT walls take from $17 \%$ to $38 \%$ from the total amount, showing margins of improvement for further steps. In order to increase the global stiffness and consequently improving the performance against frequent earthquakes, the insertion of steel prestressed cables within the layers of the CLT walls (vertically) could be investigated (Sarti et al. 2016; Van de Kuilen and Xia 2014). An increased stiffness at the foundation interface between the CLT walls and the concrete could then be provided exploiting the rocking mechanisms, with a consequent reduction of connectors (hold-downs and angular brackets). 
Additionally, the insertion of dissipative devices at the level of the connections with the existing structure could decrease the global seismic demand. The current selection of connectors was, in fact, intended to minimise the variables in the numerical analyses.

Finally, a rapid assembly procedure concerning the structure is shown to underline advantages of using lightweight timber products, with respect to steel or concrete counterparts, and the level of prefabrication of the various elements with a consequent optimization of construction time. With the same logic prefabricated technological architectural solutions constitute the finishing "layer" of the renovation, providing an efficient energetic envelope and three possibilities of spacing units.

Declarations This article is part of the Pro-GET-onE project which has received funding from the European Union's Horizon 2020 Innovation action under grant agreement No 723747.

The authors have no relevant financial or non-financial interests to disclose.

\section{References}

Aondio, P., P. Glaser and H. Kreuzinger. 2020a. Fe-berechnung von geklebtem brettsperrholz - teil 2: Beispiele. Bauingenierur 95, no 2: 4.

Aondio, P., P. Glaser, H. Kreuzinger and P.G. P. Aondio, H. Kreuzinger. 2020b. Fe-berechnung von geklebtem brettsperrholz - teil 1: Theorie. Bauingenieur 95, no 1: 4.

Assimakopoulos, M.-N., R.F. De Masi, D. Papadaki, S. Ruggiero and G.P. Vanoli. 2018. Energy audit and performance optimization of a residential university building in heating dominated climates of italian backcountry TEMA 4, no Special Issue: 15.

Badini, L., C.A. De Stefano, A. Custodi, G. Predari and A. Ferrante. 2019. Seismic strengthening of existing rc structure through external 3d exoskeleton. In IABSE Congress, New York City, 2019, ed. Iabse, 1018-24. New York.

Barmparesos, N., D. Papadaki, M. Karalis, K. Fameliari and M.N. Assimakopoulos. 2019. In situ measurements of energy consumption and indoor environmental quality of a pre-retrofitted student dormitory in athens. Energies 12, no 11: 2210 .

BBV Systems, Post-tensioning systems. www.bbv-systems.com.

CSI 2018. Etabs ultimate v17.0.1. Integrated Building Design Software. Berkeley (CA, USA): Computers \& Structures Inc.

Dangel, U. 2018. "Tall wood buildings: Design, construction, and performance” by michael green and jim taggart. Technology|Architecture + Design 2, no 2: 254-56.

Dujic, B., T. Assistant and R. Zarnić. 2008. Shear capacity of cross-laminated wooden walls.

Dujic, B., K. Pirmanšek, R. Zarnić and A. Ceccotti. 2010. Prediction of dynamic response of a 7-storey massive xlam wooden building tested on a shaking table. World Conference on Timber Engineering.

European Committee for Standardization (CEN), 2002. EN 1991-1-1: Eurocode 1: Actions on structures - part 1-1: General actions - densities, self-weight, imposed loads for buildings. Brussels, Belgium.

European Committee for Standardization (CEN), 2004a. EN 1992-1-1: Eurocode 2: Design of concrete structures - part 1-1: General rules and rules for buildings. Brussels, Belgium.

European Committee for Standardization (CEN), 2004b. EN 1995-1-1: Eurocode 5: Design of timber structures - part 1 1: General - common rules and rules for buildings. Brussels, Belgium.

European Committee for Standardization (CEN), 2004c. EN 1998-1: Eurocode 8: Design of structures for earthquake resistance - part 1: General rules, seismic actions and rules for buildings. Brussels, Belgium.

European Committee for Standardization (CEN), 2005. EN 1998-3: Eurocode 8: Design of structures for earthquake resistance - part 3: Assessment and retrofitting of buildings. Brussels, Belgium.

Fédération internationale du béton (fib), Seismic Assessment and Retrofit of Reinforced Concrete Buildings: State-ofthe-art report. International Federation for Structural Concrete (fib), Lausanne, Switzerland, 2003. ISSN 1562 3610.

Feroldi F. et al., "Miglioramento e adeguamento sismico di edifici contemporanei mediante approccio integrato energetico, architettonico e strutturale con soluzioni a doppio involucro a minimo impatto ambientale," PROGETTAZIONE SISMICA, vol. 5, pp. 31-47, 01/01 2014, doi: 10.7414/PS.5.2.31-47.

Ferrante, A., A. Fotopoulou, G. Semprini, D. Cantelli, S. Ruggiero, M. Karalis, C. Efthymiou, D. Papadaki and M.-N. Assimakopoulos. 2019. Ieq and energy improvement of existing buildings by prefabricated facade additions: The case of a student house in athens, 042047. 
Ferrante, A., G. Mochi, G. Predari, L. Badini, A. Fotopoulou, R. Gulli and G. Semprini. 2018. A european project for safer and energy efficient buildings: Pro-get-one (proactive synergy of integrated efficient technologies on buildings' envelopes). Sustainability 10, no 3: 812 .

Fotopoulou, A., L. Badini, G. Mochi, G. Predari, R. Roijakkers and R. Cojocaru. 2018. Seismic strengthening through external exoskeleton. TEMA 4, no Special Issue: 18.

Fotopoulou, A., A. Ferrante, L. Badini, G. Predari, G. Mochi, G. Semprini, R. Gulli, M. Assimakopoulos and D. Papadaki. 2019. An integrated system for façade additions combining safe, energy efficient and userorientated solutions TEMA 5, no 1: 10 .

Gavric, I., M. Fragiacomo and A. Ceccotti. 2015. Cyclic behaviour of typical metal connectors for cross-laminated (CLT) structures. Materials and Structures 48, no 6: 1841-57.

Giardini, D., J. Woessner and L. Danciu. 2014. Mapping europe's seismic hazard. EOS, Transactions American Geophysical Union 95.

Granello, G., A. Palermo, S. Pampanin, S. Pei and J.V.D. Lindt. 2020. Pres-lam buildings: State-of-the-art. Journal of Structural Engineering 146, no 6: 04020085.

Gräfe, M., P. Dietsch and S. Winter. 2018. CLT under in-plane loads: Investigation on stress distribution and creep.

Guardigli, L., M.A. Bragadin, A. Ferrante and R. Gulli. 2019a. Life cycle analysis and planning in the renovation process of public housing TEMA 5, no 2: 14.

Guardigli, L., C. Ferrer, C. Peters, A. Fotopoulou, M.A. Bragadin and A. Ferrante. 2019b. Rehabilitation of public housing buildings in a life cycle perspective, 012038 .

Hristovski, V., B. Dujic, N. Naumovski and M. Garevski. 2018. Shaking-table tests and comparative numerical investigation of various upgrade systems on existing RC structures.

Jeitler, G., M. Augustin and G. Schickhofer. 2016. Birch glt\&clt: Mechanical properties of glued laminated timber and cross laminated timber produced with the wood species birch. In WCTE 2016 - World Conference on Timber Engineering.

Kontadakis, A., A. Tsangrassoulis, L. Doulos and S. Zerefos. 2018. A review of light shelf designs for daylit environments. Sustainability 10, no 1: 71.

Lattke, F., K. Larsen, S. Ott and Y. Cronhjort. 2011. Tes energy facade - prefabricated timber based building system for improving the energy efficiency of the building envelope, funded by: Woodwisdom net, research project from 2008-2009.

Maheri M. R., R. Kousari, and M. Razazan, "Pushover tests on steel X-braced and knee-braced RC frames," Engineering Structures, vol. 25, no. 13, pp. 1697-1705, 2003/11/01/ 2003, doi: https://doi.org/10.1016/S01410296(03)00150-0.

Margani, G., G. Evola, C. Tardo and E.M. Marino. 2020. Energy, seismic, and architectural renovation of RC framed buildings with prefabricated timber panels. Sustainability 12, no 12: 4845.

Maslaev Consulting, 2015. Technical assessment report - civil engineering works regarding the change of destination from dormitory to community housing: Str. Zizinului no. 126c, brasov, romania. Civil engineering works regarding the change of destination from dormitory to community housing. Brasov, Romania.

Mora, T.D., A. Righi, F. Peron and P. Romagnoni. 2015. Functional, energy and seismic retrofitting in existing building: An innovative system based on XLAM technology. Energy Procedia 82: 486-92.

Ott, S. and M. Krechel. 2018. Construction principles of seismic and energy renovation systems for existing buildings. TEMA 4, no Special Issue: 15.

Palermo, A., S. Pampanin, A.H. Buchanan and M.P. Newcombe. 2005. Seismic design of multi-storey buildings using laminated veneer lumber (LVL).

Pihelo, P., T. Kalamees and K. Kuusk. 2017. Nzeb renovation with prefabricated modular panels. Energy Procedia 132: 1006-11.

Priestley, M., S. Sritharan, J. Conley and S. Pampanin. 1999. Preliminary results and conclusions from the presss fivestory precast concrete test building. PCI Journal 44.

Pro-GET-onE Consortium (NKUA, ABT and UNIBO). 2018. D2.6: Sheets on technical data on the case studies. In Proactive synergy of integrated Efficient Technologies on buildings' Envelopes: Pro-GET-onE.

Sarti, F., A. Palermo and S. Pampanin. 2016. Quasi-static cyclic testing of two-thirds scale unbonded posttensioned rocking dissipative timber walls. Journal of Structural Engineering 142, no 4: E4015005.

Stazi, F., M. Serpilli, G. Maracchini and A. Pavone. 2019. An experimental and numerical study on clt panels used as infill shear walls for RC buildings retrofit. Construction and Building Materials 211: 605-16.

Sustersic, I. and B. Dujic. 2012. Seismic strengthening of existing buildings with cross laminated timber panels. Paper presentat at the World Conference on Timber Engineering 2012, WCTE 2012.

Sustersic, I. and B. Dujic. 2013. Seismic strengthening of existing URM and RC structures using XLAM timber panels.

Sustersic, I. and B. Dujic. 2014a. Seismic shaking table testing of a reinforced concrete frame with masonry infill strengthened with cross laminated timber panels.

Sustersic, I. and B. Dujic. 2014b. Seismic strengthening of existing concrete and masonry buildings with crosslam timber panels, 713-23. Dordrecht: Springer Netherlands.

Sustersic, I., B. Dujic and S. Gostič. 2010. Timber upgrade of structures on seismically active areas. 
Sustersic, I., M. Fragiacomo and B. Dujic. 2016. Seismic analysis of cross-laminated multistory timber buildings using code-prescribed methods: Influence of panel size, connection ductility, and schematization. Journal of Structural Engineering 142, no 4: E4015012.

Van De Kuilen, J.W.G. and Z. Xia. 2014. Lateral behavior of post-tensioned cross laminated timber walls using finite element analysis. Paper presentat at the WCTE 2014: Proceedings of the World Conference on Timber Engineering, Quebec, Canada, 10-14 August 2014, 2014-08-10.

Wanninger, F. 2015. Post-tensioned timber frame structures. Doctoral Thesis.

Wanninger, F. 2017. Fast assembled post-tensioned timber frames. Paper presentat at the 7e Forum International Bois Construction, FBC 2017.

Wanninger, F. and A. Frangi. 2014. Experimental and analytical analysis of a post-tensioned timber connection under gravity loads. Engineering Structures 70: 117-29.

Wanninger, F. and A. Frangi. 2016. Experimental and analytical analysis of a post-tensioned timber frame under horizontal loads. Engineering Structures 113: 16-25.

Wanninger, F., A. Frangi and M. Fragiacomo. 2015. Long-term behavior of posttensioned timber connections. Journal of Structural Engineering 141, no 6: 04014155. 